\title{
Resveratrol: Latest Scientific Evidences of its Chemical, Biological Activities and Therapeutic Potentials
}

\author{
Nur Mursyida Saad', Mahendran Sekar',*, Siew Hua Gan², Pei Teng Lum¹, Jaishree Vaijanathappa ${ }^{3}$, Subban \\ Ravi $^{4}$
}

Nur Mursyida Saad', Mahendran Sekar ${ }^{1, *}$, Siew Hua Gan ${ }^{2}$, Pei Teng Lum', Jaishree Vaijanathappa ${ }^{3}$, Subban Ravi ${ }^{4}$

'Department of Pharmaceutical Chemistry, Faculty of Pharmacy and Health Sciences, Universiti Kuala Lumpur Royal College of Medicine Perak, Ipoh - 30450, Perak, MALAYSIA.

${ }^{2} S c h o o l$ of Pharmacy, Monash University Malaysia, Bandar Sunway 47500, Selangor Darul Ehsan, MALAYSIA.

${ }^{3}$ Department of Pharmaceutical Chemistry, JSS College of Pharmacy, Mysuru - 570015, JSS Academy of Higher Education and Research, Mysuru, Karnataka, INDIA. ${ }^{4}$ Department of Chemistry, Karpagam Academy of Higher Education, Coimbatore640 021, Tamil Nadu, INDIA.

\section{Correspondence}

\section{Assoc. Prof. Dr. Mahendran Sekar}

Department of Pharmaceutical Chemistry, Faculty of Pharmacy and Health Sciences, Universiti Kuala Lumpur Royal College of Medicine Perak, Ipoh - 30450, Perak, MALAYSIA.

Phone no: (6016) - 3346653;

Fax: (605) - 2536634

E-mail: mahendransekar@unikl.edu.my

History

- Submission Date: 18-07-2020;

- Review completed: 04-09-2020;

- Accepted Date: 10-09-2020

DOI : 10.5530/pj.2020.12.240

Article Available online http://www.phcogj.com/v12/i6s

\section{Copyright}

(c) 2020 Phcogj.Com. This is an openaccess article distributed under the term of the Creative Commons Attribution 4.0 International license.

\section{ABSTRACT}

Background: Resveratrol is a non-flavonoid polyphenol possesses many biological properties with great potential to develop into various products. In order to cure a wide variety of diseases, resveratrol has attracted a great deal of attention for medicinal purposes. Objective: The present review aimed to provide a comprehensive literature summary of latest scientific evidences on the chemistry, biological properties and therapeutic potentials of resveratrol. Methods: To complete this review, relevant literatures were collected from several scientific databases, including Google Scholar, Pubmed and ScienceDirect, using keywords "source", "chemistry", "bioavailability", "pharmacokinetics", "isolation", "anticancer", "analgesic", "antiinflammatory", "antidiabetic", "nephroprotective activity", "neuroprotective activity", "antiobesity," "cardioprotective effects", "antioxidant," "anti-aging" with resveratrol. After a detailed screening process for inclusion and exclusion, the information obtained was summarised. Results: The information on the source, chemistry, bioavailability, biological and therapeutic potentials of resveratrol were tabled. In various pathological conditions, resveratrol can be considered as powerful antioxidants along with multidimensional molecular targets such as NF-KB, MAPK, AMPK, SIRT-1, Nrf-2, m-TOR, PI3K/Akt and PPAR- $\gamma$ signaling pathways. Conclusion: Based on the existing knowledge, we may believe that resveratrol has a significant therapeutic potential for the treatment of various diseases. To accelerate the development and utilization of resveratrol as promising products, in-depth studies should be focused on exploiting its properties and developing phytopharmaceuticals.

Key words: Resveratrol, Bioavailability, Pharmacology, Toxicity, Molecular targets, Inflammatory cytokines.

\section{INTRODUCTION}

Resveratrol is a naturally occurring non-flavonoid phytoalexin that belong to the class of polyphenolic compounds called stilbenes. This secondary metabolite is produced by plants in response to stressful conditions ${ }^{1,2}$ Resveratrol was first isolated by a Japanese scientist, Michio Takaoka from the Veratrum grandiflorum or white hellebore plant in 1940. ${ }^{3,4}$ Later, in 1963, Nomomura isolated resveratrol from the Japanese knotweed or Polygonum cuspidatum. ${ }^{5}$

In fact, resveratrol is widely used in many renowned traditional Chinese medicine (TCM) formulations and registered in the Chinese Pharmacopoeia. ${ }^{6}$ In 1992, resveratrol was also found in wine by Siemann and Creasy. ${ }^{4}$ Resveratrol is likewise, one of the most essential bioactive elements present in grapes (Vitis vinifera) and is a natural phytoalexin that accumulates in the skins of fruits or stems and roots of the plant due to environmental stimulation. $^{7}$ It is also found in glycosylated forms in fruits such as berries, raw peanuts and red currant. ${ }^{5,8}$ Resveratrol is also known as the "French Paradox"1; a phenomenon that occurred in France based on an epidemiological data, in which the French were seen to have a low incidence of coronary heart diseases despite having a diet that is high in saturated fat. This phenomenon created great interest among researchers to understand the reason behind the relationship. One of the researchers' team was Renaud and de Lorgeril who found that more than $50 \%$ of the total alcohol consumption in France consists of moderate intake of wine, thus suggesting that the protective effect on coronary heart diseases may be contributed by a decreased platelet aggregation. ${ }^{9,10}$

Many review of resveratrol have so far concentrated on the individual biological properties of resveratrol including anticancer, antidiabetic and antiinflammatory activities of resveratrol..$^{2-5}$ However, there is no latest and updated comprehensive review of scientific evidences available especially on the chemical, biological and therapeutic potential of resveratrol. Hence, in the present study, we aimed to conduct a narrative literature review and provide its comprehensive summary focusing on the sources, distribution, chemistry, bioavailability, biological properties, toxicity profile, tolerability as well as applications in food products.

\section{METHODS}

To complete this review, relevant literatures were collected from several scientific databases, including Google Scholar, Pubmed and ScienceDirect. The categories of keywords used for the search 
were "Resveratrol" and "Pharmacological Studies" or "Biological Studies" or "Source" or "Chemistry" or "Isolation" or "Anticancer" or "Analgesic" or "Anti-inflammatory" or "Antidiabetic" or Nephroprotective Activity" or "Neuroprotective activity" or "Antiviral" or "Anti-obesity" or "Cardioprotective Effects" or "Antioxidant" or "Anti-aging" or "Toxicity" or "Bioavailability" or "Pharmacokinetics" etc. Studies not written in English and which have no abstracts were excluded from initial screening. There was no restriction to be followed for collecting the resveratrol-related studies, especially in the aspects of dose, route of administration, duration of treatment, animal and human study. The articles were chosen for final analysis after applying the inclusion and exclusion criteria and removing duplicates from the databases. The information included in the review was separated into two main categories: phytochemical and pharmacological properties of resveratrol. Additionally, they were categorised according to the main findings of the study. Following a complete screening, the information obtained were summarized and were included in the present review.

\section{PLANT SOURCES AND DISTRIBUTION OF RESVERATROL}

Resveratrol is reported to be present in almost 72 plant species, scattered around 31 genera and 12 families. The families are Myrtaceae, Vitaceae, Cyperaceae, Dipterocarpaceae, Pinaceae, Gnetaceae, Fabaceae, Moraceae, Liliaceae and Fagaceae; from the spermatophytes division. ${ }^{11}$ Historically, a Japanese scientist was the first to detect resveratrol in the roots of Veratrum grandiflorum and later resveratrol was isolated from the roots of Polygonum cupsidatum. ${ }^{12}$ Polygonum cuspidatum ( $P$. cupsidatum) is an herbaceous perennial and is a member of the genus Polygonum in the Polygonaceae family. The herb grows in Asia as well as in North America. There are approximately 80 species of Polygonum utilised in Traditional Chinese Medicine. Its dried root is officially listed in the Pharmacopoeia of the People's Republic of China under the name "Hu Zhang", while in Japan and Korea, it is used as folk medicine. ${ }^{13}$ The roots, stems, leaves, flowers, fruits and seeds are commonly used for extraction. ${ }^{11}$

In recent years, resveratrol mainly is found in grapes and grape products ${ }^{14}$, but only in the trans-isomer resveratrol. ${ }^{15}$ Both isomers have been detected in red wine, while peanut and peanut butter ${ }^{16}$ contained only a minimal amount of trans-resveratrol, i.e. below the limit of quantification. ${ }^{15}$ Trans-resveratrol can also be detected in stems, leaves and root of Itadori plants as well in its tea. ${ }^{15}$ Resveratrol is also discovered in cacao (Theobroma cacao) ${ }^{17}$ and various types of berries including blueberries, bilberries and cranberries, which belongs to the Vaccinium species. ${ }^{18}$ Additionally, red wine, initially produced by fermentation of grapes and different type of wines contained different amounts of resveratrol. ${ }^{19,20}$ Trans-resveratrol is mainly found in red wine as opposed to white wine since grape's skin has to be removed in the process of making white wine $\mathrm{e}^{21}$ and most resveratrol is in the skin itself.

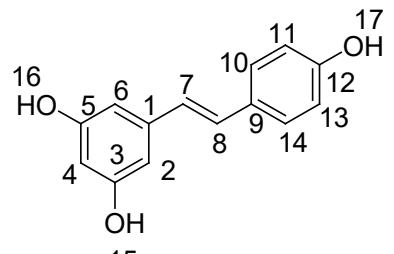

15

trans-Resveratrol

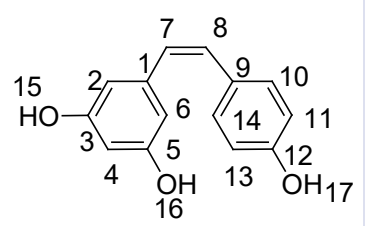

cis-Resveratrol
Figure 1: Chemical structures of trans- and cis-resveratrol's.

\section{CHEMISTRY}

Generally, resveratrol is composed of two aromatic rings which are connected by a methylene bridge. It naturally exists in isomeric forms, i.e. trans and cis-resveratrol's (Figure 1) with the former showing most of the reported biological activities. ${ }^{22}$ Structurally, the two phenolic rings of resveratrol are linked by a double bond. ${ }^{5,23}$ Cis-resveratrol is isomerized from trans-resveratrol when exposed to sunlight, UV radiation or when being heated. ${ }^{24-26}$ The trans-isomer is the most stable resveratrol and is more commonly detected ${ }^{27}$ besides being biologically active. $^{21}$

\section{Isolation of Resveratrol}

\section{Isolation from Grapes and Peanut Products}

Different isolation methods are used for different sources of resveratrol. For isolation from grapes, frozen grapes $(10 \mathrm{~g})$ were defrosted at room temperature and were homogenized with methanol $(30 \mathrm{ml})$ containing formic acid (2\%). ${ }^{28}$ Subsequently, the mixture was centrifuged at 10,000 $\mathrm{g}$ for approximately $10 \mathrm{~min}$ and the supernatant was stored at $-80^{\circ} \mathrm{C}$. On the other hand, for isolation from peanuts, approximately $33 \mathrm{mg}$ of peanuts (or $75 \mathrm{mg}$ for smooth peanut butter) was extracted overnight with $50 \%$ methanol $(1 \mathrm{ml})$. The aqueous supernatant was then stored at $-80{ }^{\circ} \mathrm{C}$ following centrifugation, before pure resveratrol was yielded. ${ }^{28}$

\section{Isolation from P. cuspidatum}

Stems and leaves: The tissues were lyophilized before an overnight extraction with $50 \%$ methanol $(1 \mathrm{ml}) .{ }^{15}$ Approximately $10 \mathrm{mg}$ aliquots were used to obtain pure resveratrol.

Dried root: In a distillation flask, powdered roots (100 g) were added to 95\% ethanol (1:6) (powder: 95\% ethanol, $\mathrm{g} / \mathrm{ml}$ ). Then, the mixture was left to rest ( $12 \mathrm{~h}$ at room temperature). Next, a refluxing extraction (80 ${ }^{\circ} \mathrm{C}$ ) was used to extract the soaked powder. The extraction procedures were repeated thrice for $1 \mathrm{~h}$ each time. The extract solutions were mixed and evaporated to dryness by using a rotary evaporator under vacuum at $65{ }^{\circ} \mathrm{C}$. Subsequently, resveratrol was detected by high performance liquid chromatography (HPLC). ${ }^{6}$

\section{Isolation from Itadori root}

Itadori tea was prepared by infusing a sample $(1 \mathrm{~g})$ of dried commercial Itadori root (Kojoukon) with boiling water $(100 \mathrm{ml})$ for $5 \mathrm{~min}$. Then, the mixture was filtered. Finally, $1 \mathrm{ml}$ aliquots of the tea was stored at $-80{ }^{\circ} \mathrm{C}$, yielded resveratrol..$^{15}$

\section{Spectral Data of Resveratrol}

${ }^{1}$ HNMR (DMSO, $400 \mathrm{MHz}$ ): ${ }^{1} \mathrm{H}$ NMR data indicated that alkene hydrogens at the $\mathrm{C} 7$ and $\mathrm{C} 8$ positions were observed as two doublets at $\delta 6.79$ and 6.90 with a coupling constant $J=15.28 \mathrm{~Hz}$ which confirms the trans orientation of the two alkene hydrogens. The three phenolic hydrogens were observed as a broad signal $\delta 9.30(\mathrm{~s}, 3 \mathrm{H}, \mathrm{H}-15, \mathrm{H}-16$ and $\mathrm{H}-17)$ integrated for three protons which disappeared on $\mathrm{D}_{2} \mathrm{O}$ exchange studies. The aromatic hydrogen between the two hydroxyl substituents at the $\mathrm{C} 4$ position was found to be shielded to $\delta 6.10$ as a triplet with a meta coupling constant of $J=2.1 \mathrm{~Hz}$. The hydrogens at the 2 and 6 positions were shielded to $\delta 6.37$ and appear as doublets with a coupling constant $\mathrm{J}=2.2 \mathrm{~Hz}$, which is a characteristic coupling constant for the aromatic hydrogens in the meta position. The remaining aromatic hydrogens at positions $10,11,13$, and 14 appear as two doublets at $\delta$ 7.38 (d, 2H, H-10, H-14), 6.74 (d, 2H, H-11, H-13) each integrated for two protons with a coupling constant of $\mathrm{J}=6.9 \mathrm{~Hz}$, which matches the coupling constant for the ortho coupling in aromatic systems, and also the splitting pattern matches the p-substituted aromatic compounds.

${ }^{13} \mathrm{CNMR}$ (DMSO, $100 \mathrm{MHz}$ ): In the ${ }^{13} \mathrm{C}$ NMR spectrum, three carbons deshielded more than the others and were observed as two signals at 
$\delta 157.3$ and 158.6 which indicate that these carbons are attached to hydroxyl groups and assigned for the C3, C5, and C12 carbons. The presence of two low intensity signals at $\delta 128.1$ and 139.4 suggested the presence of two more quaternary carbon atoms $\mathrm{C}-1$ and C-9 respectively. Due to the hydroxyl substituent effect at the ortho position, the carbons at C4, C6, C2, C11, and C13 appear more shielded at $\delta 104.4(\mathrm{C}-2, \mathrm{C}-6)$, 101.9 (C-4), $115.6(\mathrm{C}-11)$ and $115.6(\mathrm{C}-13)$. The C-7 and C-8 carbons resonated at $\delta 125.7(\mathrm{C}-7)$ and $127.9(\mathrm{C}-8)$. The $\mathrm{C}-10, \mathrm{C}-14$ carbons also resonated at $\delta 127.9$.

\section{Mass Spectrum}

Wang et al. ${ }^{6}$ reported the HPLC electrospray ionisation tandem mass spectroscopy (HPLC-ESI-MS/MS) of resveratrol. The molecular ion peak was at $\mathrm{m} / \mathrm{z} 227$. The fragmentation peaks were $185,143,117$ and 119.

\section{PHARMACOKINETICS AND BIOAVAILABILITY OF RESVERATROL}

Following a $4 \mathrm{~h}$ of low dose (single dose of $0.5 \mathrm{~g}$ ) administration, urinary excretion of resveratrol was rapid at $77 \%{ }^{29}$ The pharmacokinetic analysis of resveratrol indicated that it has an unusually high (at least 70\%) bioavailability. ${ }^{30,31}$ In a study by Vitrac et al. ${ }^{32}$, the concentration of a radioactive, 14 -trans-resveratrol was highest after $1.5 \mathrm{~h}$ of administration in organs including the stomach, intestine, liver and kidney of rats. Fast absorption is affected by food with high fat content which may reduce and delay resveratrol's absorption. ${ }^{33}$ The oral bioavailability of unchanged resveratrol is relatively low (almost zero) ${ }^{31,32}$ which may be contributed by the extensive metabolism of resveratrol ${ }^{30,31}$, thus indicating that the low oral bioavailability is contributed mainly by sulfate conjugation and glucuronidation processes by enterocytes. ${ }^{30}$ Eight resveratrol metabolites (Figure 2) were documented by Springer and $\mathrm{Moco}^{34}$. Within the background of metabolic health and obesity, they explored human metabolism and biotransformation of resveratrol, and identified molecular mechanisms of action. ${ }^{34}$

Although resveratrol was absorbed after oral administration, due to its rapid and extensive phase II metabolism, its plasma concentration and tissue distribution were low. ${ }^{1}$ According to Walle et al. ${ }^{31}$, a metabolite which is the sulfate conjugate was measurable in plasma samples within $2 \mathrm{~h}$ following either intravenous or oral administration of resveratrol. The rapid production of metabolite indicates that the rate limiting factor to its bioavailability is sulfation. Resveratrol metabolites are largely characterized into two mono-sulfates, one di-sulfate, two monoglucuronides and one glucuronide-sulfate. ${ }^{29}$ Trans-resveratrol-3-Oglucuronide and trans-resveratrol-3-sulfate are the utmost metabolites since both are significantly found in rat urine and mouse serum; formed by rat hepatocytes although trans-resveratrol-3-O-glucuronide is detected in the human liver as the primary metabolite..$^{35}$ The main route of elimination of resveratrol is via urine in which a high concentration of radioactive, 14-trans-resveratrol was found compared to via the fecal route. ${ }^{31,32}$

Recent studies tend to focus on enhancing resveratrol's bioavailability. Amiot et al. ${ }^{36}$ formulated a soluble trans-resveratrol by solubilizing natural trans-resveratrol from P. cuspidatum in a complex lipid solution without any molecular modification. They found that a single dose of the new formulation $(40 \mathrm{mg})$ was well absorbed since it yielded an 8.8fold higher plasma trans-resveratrol levels as compared to the original powder. On the other hand, the oral bioavailability of resveratrol is

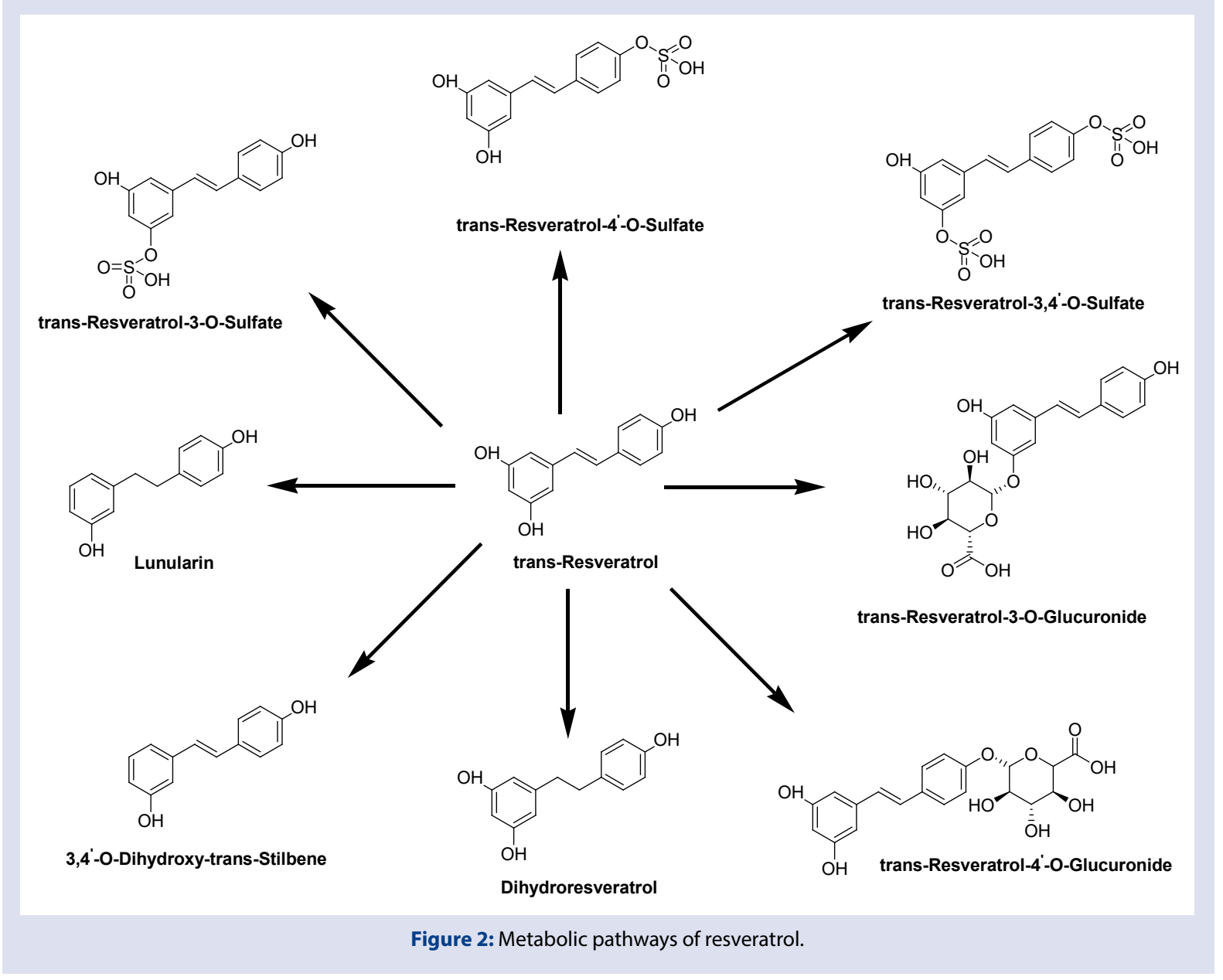


enhanced (close to $26.5 \%$ ), by encapsulating it into casein nanoparticles by 10 times as compared to when administered in the oral solution. Casein nanoparticles reach the surface of the gut epithelium as well as control the release of resveratrol, thus help in enhancing its absorption as well as bioavailability. ${ }^{37}$ Next, by using a liquid micellar water formulation on grapevine extract, the amount of trans-resveratrol was five-fold higher following its since micellar solubilization increased its hydrophilicity. ${ }^{38}$

\section{BIOLOGICAL ACTIVITIES AND THERAPEUTIC POTENTIALS OF RESVERATROL}

Resveratrol has many useful biological activities and therapeutic potential, and some important underlying molecular action mechanism for the related activities has been described (Figures 3 and 4) and summarised in Table 1.

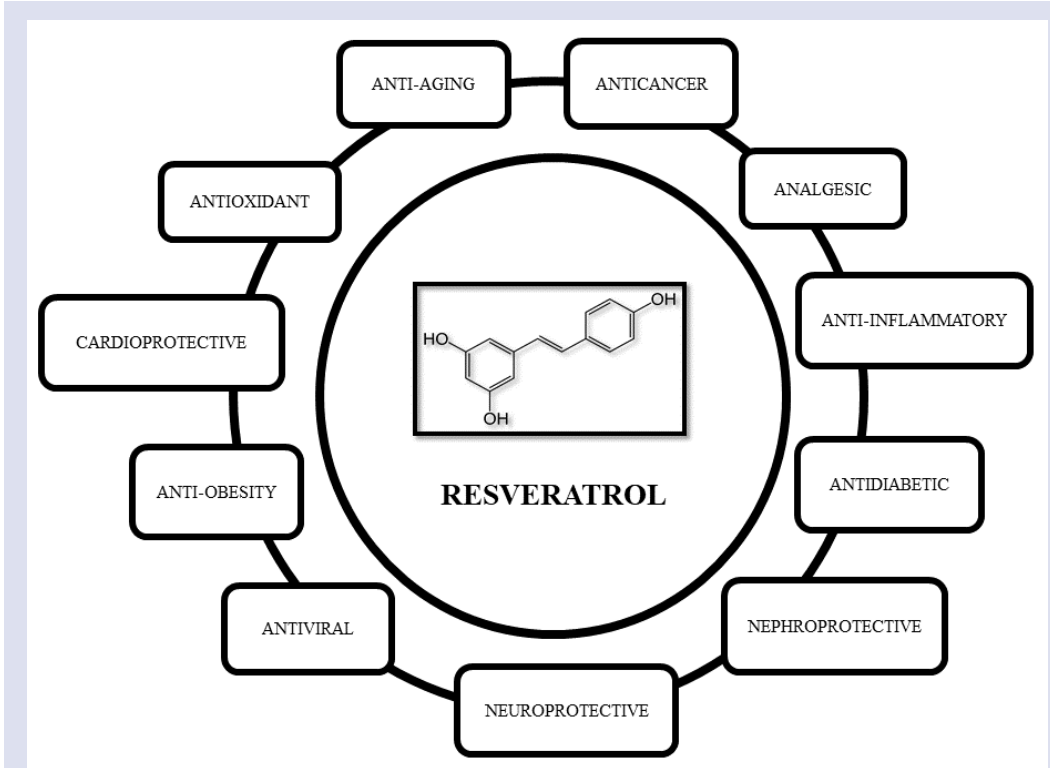

Figure 3: Biological activities and therapeutic potentials of resveratrol.

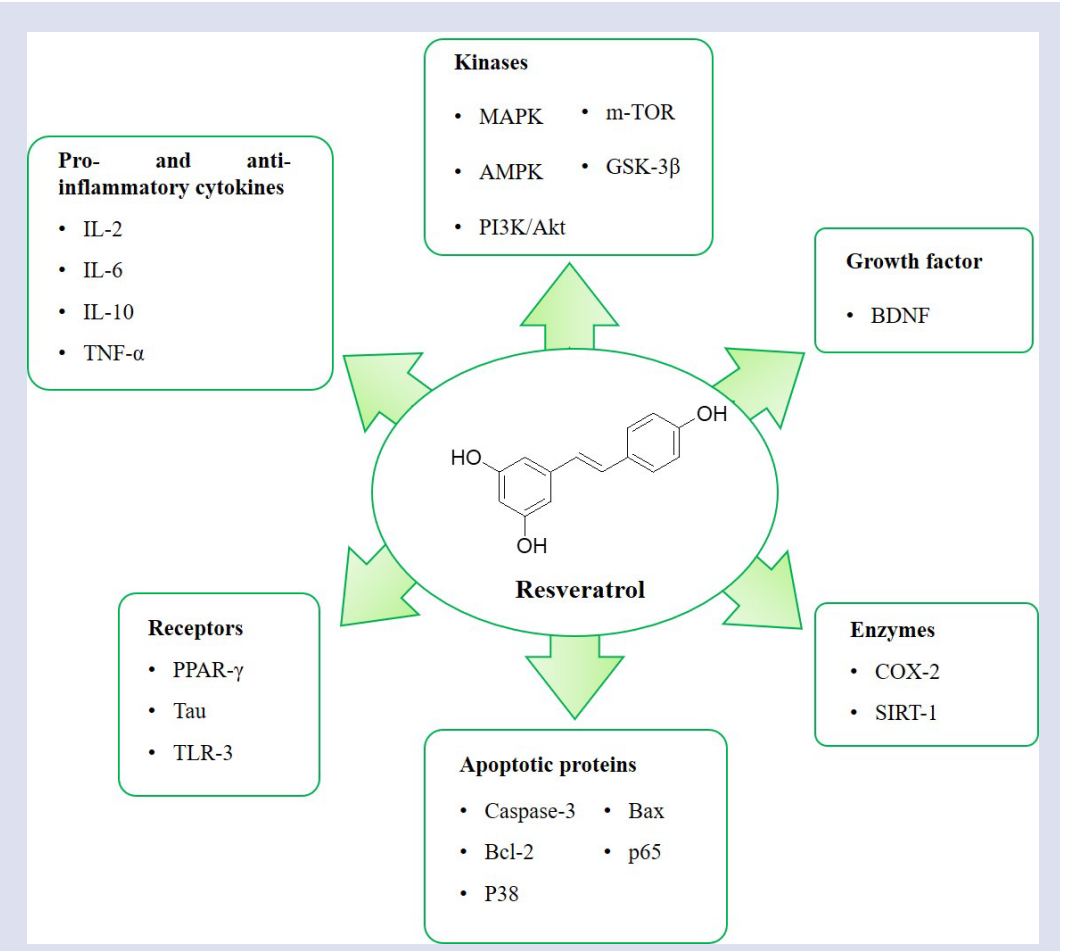

Figure 4: Multiple molecular targets of resveratrol. It could modulates multiple molecular targets by modifying their gene expression, signaling pathways, or via direct interaction. The detailed information has been summarized in Table 1. All the abbreviations are available in the main text. 
Table 1: An overview of some important underlying molecular mechanisms for different biological properties of resveratrol.

\begin{tabular}{|c|c|c|}
\hline Biological Property & Mechanism & Reference \\
\hline Anticancer & 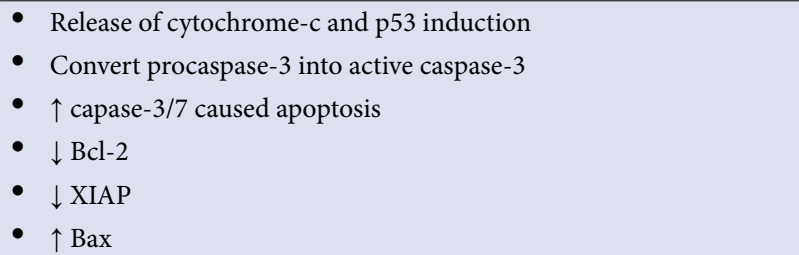 & $\begin{array}{l}\text { Rajasekaran et al. }{ }^{46} ; \text { Shankar et } \\
\text { al. } .^{47} ; \text { Zhou et al. }{ }^{33}\end{array}$ \\
\hline Analgesic and Anti-inflammatory & $\begin{array}{l}\text { - Down-regulates } \mathrm{p} 53 \text { and } \mathrm{p} 53 \text {-phospho-Ser15 } \\
\text { - } \downarrow \text { COX-1 and COX-2 activation } \\
\text { - } \quad \downarrow \text { ROS }\end{array}$ & $\begin{array}{l}\text { Jang et al. }{ }^{43} \text {; Cui et al. }{ }^{45} ; \text { Ko et } \\
\text { al. } .^{58} ; \text { Wang et al. }{ }^{62}\end{array}$ \\
\hline Antidiabetic & $\begin{array}{l}\text { - Up-regulation of GLUT-4 } \\
\text { - } \quad \downarrow \text { Insulin resistance } \\
\text { - } \uparrow \beta \text {-cell/islet area ratio } \\
\text { - } \quad \downarrow \text { Oxidative stress (OS) } \\
\text { - } \uparrow \text { Glucose utilization }\end{array}$ & $\begin{array}{l}\text { Movahed et al. }{ }^{64} ; \text { Dash et al }{ }^{65} ; \\
\text { Knop et al } .^{66} \text { G González-Rodrí- } \\
\text { guez et al. }{ }^{106}\end{array}$ \\
\hline Neuroprotection & 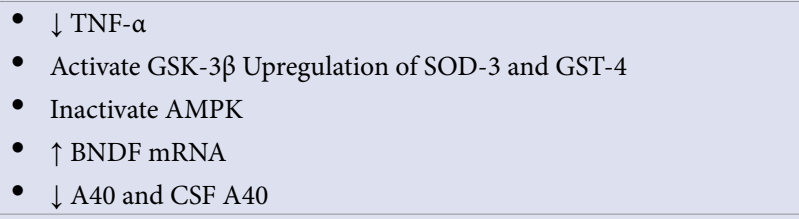 & $\begin{array}{l}\text { Jeon et al. } .^{71} \text {; Liang et al. }{ }^{72} \\
\text { Wiciński } \text { et al. }^{74} \text {; Sawda et al. }\end{array}$ \\
\hline Antiviral & 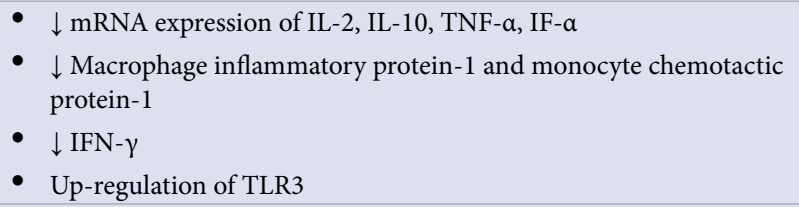 & $\begin{array}{l}\text { Huang et al. }{ }^{76} \text {; Abba et al. }{ }^{77} \text {; Zang } \\
\text { et al. }\end{array}$ \\
\hline Anti-obesity & $\begin{array}{ll}\text { - } & \downarrow \text { PPAR } \gamma \\
\text { - } & \downarrow \text { SIRT- } 1 \text { and PGC1 } \alpha\end{array}$ & Zhao et al. ${ }^{80}$; Floyd et al..$^{81}$ \\
\hline Cardioprotection & $\begin{array}{l}\text { - } \text { Regulates eNOS } \\
\text { - } \quad \uparrow \text { AMPK } \\
\text { - } \quad \downarrow \text { p70 S6 kinase pro-hypertrophic signaling cascade } \\
\text { - } \text { Regulates PI3-kinase-Akt-Bcl-2 }\end{array}$ & $\begin{array}{l}\text { Bonnefont-Rousselot }{ }^{83} \text {; Leikert } \\
\text { et al }{ }^{84} ; \text { Dolinsky et al. }{ }^{85} \text {; Göçmen } \\
\text { et al. }{ }^{88}\end{array}$ \\
\hline Antioxidant & 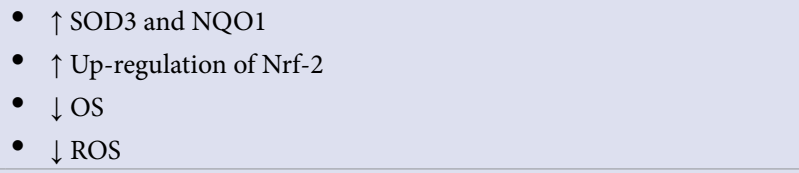 & $\begin{array}{l}\text { Chatterjee et al. } .^{89} \text {; Gerszon et } \\
\text { al. } .^{90} \text {; Iuga et al. }{ }^{91}\end{array}$ \\
\hline Anti-aging & $\begin{array}{l}\text { - Up-regulation of AMPK/SIRT-1/PGC-1- } a \\
\text { - Down-regulation of Akt/mTOR } \\
\text { - } \text { Regulation of SIRT-1 } \\
\text { - } \downarrow \text { OS }\end{array}$ & Wang et al..$^{92} ; \mathrm{Li}$ et al..$^{93} ;$ Baxter $^{94}$ \\
\hline Nephroprotection & $\begin{array}{l}\text { - } \quad \uparrow \text { HSP70 and p-IкBa expression } \\
\text { - } \quad \downarrow \text { p-65 } \\
\text { - } \uparrow \text { Endogenous antioxidant system } \\
\end{array}$ & Feng et al. ${ }^{73}$; Bilgiç et al. ${ }^{95}$ \\
\hline
\end{tabular}

Note: ${ }^{*}$ upward arrow indicates increased response and downward arrow indicates decreased response. All the abbreviations are available in the main text.

\section{Anticancer activity}

Extensive studies on resveratrol's therapeutic effects have been performed in the search for the treatment and prevention of various diseases including cancers. Resveratrol is purported to have the ability to interact with different molecular and cellular targets for cancer in both in vitro and in vivo findings. Low or moderate doses of resveratrol do not pose any side effects. ${ }^{39}$ In fact, rapid metabolism to safe glucuronate and other analogues for administration in high doses have also been confirmed. ${ }^{40}$ To date, the efficacy of resveratrol against certain types of cancer have only been investigated in a few studies. To date, studies on resveratrol only focus on in vitro and in vivo animal experiments. Therefore, there were no completed ongoing clinical or trials conducted to evaluate the associated side effects or even established confirmed therapeutics outcomes of resveratrol alone or with in combination with other anticancer drugs. ${ }^{41}$ The anti-tumor effect of resveratrol on skin cancer was investigated at 100 times molar ratio to 12-O-tetradecanoylphorbol 13-acetate (TPA), a tumor inducer used to promote and induce the in vitro Epstein-Barr early antigen activation assay in which a $57.2 \%$ inhibition against Epstein-Barr early antigen activation was seen. An in vivo study on 7,12 dimethylbenz(a) anthracene (DMBA)-induced TPA-promoted in mouse skin papilloma also showed a significant reduction in both tumor incidence and tumor multiplicity. Moreover, resveratrol at a 50 -fold molar ratio to TPA demonstrated a $60 \%$ decrease in papilloma's and $30 \%$ inhibition in the tumor incidence at 20 weeks of treatments. ${ }^{42}$ The development of DMBA-induced pre-neoplastic lesions in carcinogen-treated mouse mammary glands in culture was also repressed by resveratrol in a dosedependent manner indicating inhibition of tumor initiation, promotion and progression..$^{43}$ 
A study by Harper et al. ${ }^{44}$ showed that resveratrol from the diet prevented the development of prostate cancer by decreasing cell proliferation in transgenic adenocarcinoma of the mouse prostate (TRAMP) mice. There was a $87 \%$ reduction in poorly differentiated prostate tumor in mice treated with resveratrol as compared to controls indicating that resveratrol 1) regulates the proliferation of cell and 2) the expression of sex steroid receptor protein as well as specific growth factor signaling proteins in the prostate. Reduction in cell proliferation indicates a delay in cancer progression which may be the most significant chemopreventive effects of resveratrol. Another study indicated that resveratrol reduced tumorigenesis associated with colitis. Tumor incidence was decreased to $20 \%$ (from $80 \%$ ) in mice which had colon cancer induced by azoxymethane and dextran sodium sulphate (DSS) following treatment with resveratrol (300 ppm) which also decreased tumor multiplicity. ${ }^{45}$ Rajasekaran et al. ${ }^{46}$ investigated the effect of resveratrol in early and advanced stages of hepatocarcinogenesis in hepatocellular carcinoma (HCC). Male Wistar rats were induced by $\mathrm{N}$-nitrosodiethylamine (DEN) and were used as HCC-animal models. There was decreased in HCC, $\alpha$-fetoprotein and other liver marker serum and enzyme levels following treatment with resveratrol as compared to untreated group. At 15 to 16 weeks of the experiment, the parenchymatous tissue of the liver in DEN-induced HCC indicated some alteration and transformation, as confirmed by Hematoxylin and Eosin stain (H\&E) of the tissue sections. Additionally, there was a noticeable recovery in resveratrol-treated HCC-bearing models in both early and advanced stages as well as in the architecture of liver tissues with diminution of radiating hepatocytes and sinusoidal infiltration seen. Additionally, the activities of several serum markers enzymes including alanine aminotransferase (ALT), aspartate aminotransferase (AST), alkaline phosphatase (ALP), acid phosphatase (ACP), 5'-nucleotidase (5'-Nuc), $\gamma$-glutamyl transpeptidase $(\gamma$-GT) and lactate dehydrogenase (LDH) in the HCC models were momentously reduced following resveratrol treatment. Resveratrol treatment promotes poly (ADP-ribose) polymerase (PARP) cleavage, the release of cytochrome-c, p53 induction and conversion of procaspase- 3 into active caspase- 3 in DEN-induced HCC. ${ }^{46}$

A study by Shankar et al. ${ }^{47}$ indicated that a reduction in size and weight, as well as inhibition of pancreatic intraepithelial neoplasia (PanIN) lesions shows that resveratrol can help prevent pancreatic cancer. Resveratrol inhibit the self-renewal capacity of pancreatic cancer stem cells (PCSCs) obtained from primary tumors of human and KrasG12D mice in vitro. Additionally, the formation of primary and secondary spheroids were inhibited in pancreatic cancer stem cells (CSC) derived from KrasG12D mice in vitro, while induced activation of capase-3/7 caused apoptosis and inhibited the Bcl-2 and XIAP expressions in CSCs. Additionally, a multidrug resistance gene, ABCG2, is overexpressed and inhibited in CSCs. At the same time, resveratrol repressed the expression of vimentin, slug and snail that lead to inhibition of epithelial-mesenchymal transition and suppression of migration and invasion of CSCs. Another study indicated that resveratrol (2.5 and 10 $\mathrm{mg} / \mathrm{kg}$ ) reduced the tumor volume, tumor weight and metastasis to the lung in mice bearing highly metastatic Lewis lung carcinoma (LLC) tumor. Moreover, increase in spleen weight and reduction in thymus weight was prevented by resveratrol in LLC-bearing mice suggesting that inhibition of DNA synthesis in LLC cells and LLC-induced neovascularization as well as tube formation (angiogenesis) from human umbilical vein endothelial cells (HUVEC) were contributed by the anti-tumor and antimetastatic effects of resveratrol. ${ }^{48} \mathrm{~A}$ study on oral squamous cell carcinoma, HCPC I cell line was conducted in hamsters that have been induced by DMBA, by comparing the formulations of cream and mouthwash resveratrol-HPbCD with resveratrol alone. Resveratrol's efficacy was significantly improved by complexing with a defensive and solubilizing vehicle (2-hydroxypropyl-b-cyclodextrin,
$\mathrm{HPbCD}$ ) and when formulated as a topical agent. Resveratrol can prevent the appearance and growth of oral pre-neoplastic lesion (OPL) and OSCC in vivo. The anticancer effects on the lesions' prevalence, multiplicity, dimension and histological signs of malignancy have been demonstrated by resveratrol-HPbCD formulation especially when used as mouthwash. It was plausible that resveratrol-HPbCD formulations may prevent the progression of OPLS, or even in patients who have been operated for OSCC that have a risk for recurrence or relapse. ${ }^{49}$

Woodall et al. ${ }^{50}$ investigated resveratrol's effects on the transition from reflux esophagitis to Barrett's metaplasia to dysplasia to esophagal adenocarcinoma in an esophagoduodenal anastomosis-treated experimental rats. The rats were treated with an intraperitoneal injection of resveratrol $(7 \mathrm{mg} / \mathrm{kg})$ of or saline twice weekly. There was decreased in the 1) severity of esophagitis, 2) incidence of intestinal metaplasia and 3) incidence of esophagal adenocarcinoma shown in animals treated with resveratrol for five months as compared to saline or nonoperated control groups. ${ }^{50}$ In another study, the ability of resveratrol in inhibiting the growth of human ovarian cancer PA-1 cells, considering eEF1A2 as a potential molecular target has been performed. Since the mean volume and mass of tumors were significantly dwindled, resveratrol is believed to 1 ) repressed PA-1 cells proliferation and diminished eEF1A2 expression and 2) inhibited the development of PA-1 cells transplanted to athymic mice as well as the expression of eEF1A2 in vivo. ${ }^{51}$ The chemopreventive effect of resveratrol in inhibiting urinary bladder tumor in a nude mice xenograft model has been investigated. Resveratrol caused cytotoxic effect and induction of apoptosis in bladder cancer T24 cells in time- and dose-dependent manners. The chemopreventive effects is purported to be contributed by 1) accumulation of T24 cells at the G1 phase of the cell cycle and 2) Akt as well as p38 MAPK. ${ }^{52}$ When injected near the lesion, resveratrol significantly suppresses the growth of gastric carcinoma as it induces apoptosis of transplanted tumor cells. Apoptosis is facilitated by the down-regulation of apoptosis-regulated gene bcl-2 and upregulation of the expression of apoptosis-regulated gene Bax. Resveratrol allows apoptosis of implanted tumor cells to incur some morphological changes of chromatin condensation, chromatin crescent formation and nucleus fragmentation. ${ }^{53}$

Instability of genomic and head and neck squamous cell carcinoma (HNSCC) happened due to modifications in SMAD4 signalling and its loss. Resveratrol was investigated in nude mice for $\mathrm{FaDu}$, a type of HNSCC, xenograft growth. It showed antiproliferative, DNA damage and apoptotic effects both in vitro and in vivo in HNSCC cells, independent of SMAD4 status..$^{54}$ A study on RT-2 glioma cells-treated with resveratrol indicated that resveratrol exerted cytotoxic effects and induced glioma cell apoptosis in concentration- and time-dependent manners. Resveratrol (40 mg/kg/day) also exhibited remarkable antitumor effects on S.C. tumors, including induction of a slower tumor growth rate, a longer survival time in animals as well as a higher survival rate. At a higher dose $(100 \mathrm{mg} / \mathrm{kg} /$ day $)$, resveratrol affects intracerebral tumor and prolong animal survival without affecting the survival rate. ${ }^{55}$ Resveratrol's effect on the mouse xenograft models of human neuroblastoma and human cell lines in vitro was explored in another study. Outgrowth of the tumour was decreased by $80 \%$. With higher resveratrol dose, tumour regression associated with widespread tumour cell death occurred, the underlying mechanism of which includes direct activation of the mitochondrial intrinsic apoptotic pathway. ${ }^{56}$ The development of adjuvant chemotherapies to expand currently available treatment protocols, may confer a decreased side effects and toxicity without affecting the therapeutic efficacy. Resveratrol exerted in vitro cytotoxic effects and in-vivo anticancer effects against various type of cancer, including breast, prostate, colorectal, liver, pancreatic, lung, cavity, esophagal, ovaries, urinary bladder, stomach, head and neck, cerebral cancers as well as neuroblastoma. ${ }^{2,41,57-60}$ Based on these findings, resveratrol can be concluded to have marked anticancer activity via multifaceted molecular mechanisms. 


\section{Analgesic and anti-inflammatory activities}

Many studies have indicated that the development of diseases such as cancers, neurodegenerative, respiratory and heart diseases are caused by the chronic yet low-grade inflammation of cells. These studies have unveiled the cellular and molecular level mechanisms of underlying inflammation, but to date, no therapeutic therapies have been discussed. Interaction with multiple targets and alteration of the dysregulation inflammatory pathways as well as mediators of phytochemicals suggested a potential for the development of an affordable, novel and safe drugs to treat inflammation underlying chronic disease. Resveratrol, is a polyphenol that has gained interest purported to protect inflamed cells by directly and indirectly modulate major signaling pathways. Preclinical studies have shown some positive results, although there is little clinical evidence that demonstrates its effective therapeutic effect in humans considering resveratrol has poor water solubility and bioavailability. Nevertheless, resveratrol's potential in ameliorating inflammation in patients with chronic disease should not be denied and should be confirmed in in-depth scientific investigations and large-scale clinical trials. ${ }^{61}$

Resveratrol possessed a potent anti-inflammatory effect as shown on dextran sulfate sodium (DSS) mouse model of colitis. Resveratrol significantly increases inflammatory score, decreases the percentage of neutrophils in the mesenteric lymph nodes and lamina propria, and modulates CD3 $+\mathrm{T}$ cells that show tumour necrosis factor- $\alpha$ and interferon gamma (IFN- $\gamma$ ). In addition, resveratrol also downregulates the p53 and p53-phospho-Ser15, markers of inflammation and inflammatory stress. ${ }^{45,58}$ Unlike indomethacin and most other nonsteroidal anti-inflammatory drugs, the anti-inflammatory effects of resveratrol occur via inhibition of the hydroperoxidase activity of cyclo-oxgenase (COX)-1, although the effect is less prominent when compared to those established anti-inflammatory medications. Oxygen uptake activity was also not detected as assessed with COX-2. The antiinflammatory effects of resveratrol were performed in the inflamed rat model induced by carrageenan, where pedal edema, both in acute and chronic phases was significantly reduced. ${ }^{43,58}$ In another study, Wang et $a .^{62}$ evaluated the in vivo analgesic and anti-inflammatory properties of resveratrol. Writhing effect as induced by acetic acid and confirmed by hot plate tests were performed to evaluate the analgesic effects of resveratrol. On the other hand, 1) ear edema of mouse caused by xylene, 2) pleurisy in rat induced by acetic acid and 3) carrageenan-induced rat synovitis tests was used to test its anti-inflammatory effects. Resveratrol inhibit the writhes and improved the duration and pain threshold of mice standing on hot plate indicating its analgesic effect. Resveratrol 1) inhibited mice's ear edema 2) significantly inhibit the white blood cell in rat with pleurisy 3 ) decreased nitric oxide (NO) production and 4) promote the SOD activity in serum pleurisy exudates thus confirming its anti-inflammatory effect. As in carrageenan-induced synovitis test, resveratrol decreased serum malondialdehyde (MDA) concentration and elevated total serum superoxide dismutase (T-SOD). Thus, resveratrol could inhibit the total protein (TP), prostaglandin E2, NO and MDA expressions, making it a good polyphenol candidate for the treatment of pain and inflammation. ${ }^{62}$

\section{Antidiabetic activity}

Resveratrol have beneficial effects in experimental insulin-deficient diabetic animals, by showing antihyperglycemic effects and pancreatic $\beta$-cells protection and may therefore be used as an adjunct to available conventional treatment for type 1 diabetes. Although preliminary studies ${ }^{63}$, confirmed resevratrol's effects in type 1 diabetes, its effects on type 2 diabetes have to be further investigated. Resveratrol can improve glycemic control and decrease insulin resistance in type 2 diabetes. ${ }^{64}$ Additionally, resveratrol confer other health benefits in type 2 diabetics ${ }^{64-66}$ including reduction in diabetic complications. ${ }^{67}$
Deletion of insulin receptor substrate-2 (IRS-2), impaired hepatic insulin signaling and elevated gluconeogenesis in mice may contribute to hyperglycemia. ${ }^{68}$ Inhibition of protein tyrosine phosphatase $1 \mathrm{~B}$ (PTP1B) improves the sensitivity of peripheral insulin following resveratrol administration. The compound also increases glucose uptake via translocation of GLUT-4 into the membrane. GonzálezRodríguez et al.$^{68}$ attempted to ameliorate peripheral insulin resistance in two diabetic models, IRS-2-deficient (IRS-2-/-) mice and mice injected with streptozotocin (STZ) by resveratrol treatment or sirtuin1 (SIRT-1) overexpression. The results indicated that there was improved insulin sensitivity in IRS-2-deficient mice. Mice with IRS-2-deficient typically have high PTP1B expression levels in the liver and the muscle. Nevertheless, the PTP1B in both tissues were decreased by resveratrol administration, indicating restoration of IRS-1-mediated insulin signaling. As for STZ-diabetic mice, resveratrol restored its insulin sensitivity and hepatic insulin signaling. On the contrary, moderate over-expression of SIRT-1 did not normalize PTP1B levels or restor insulin signaling in both groups. Thus, SIRT-1 does not affect the improvement of peripheral insulin signaling in association with PTP1B inhibition when treated with resveratrol indicating that resveratrol could be an effective adjuvant for the treatment of diabetes. ${ }^{68}$ Chronic treatment of resveratrol in type 2 diabetes animal model caused significant improvement in glucose tolerance, reduced oxidative stress (OS), attenuated pancreatic islet fibrosis and preserved islet mass. The pancreatic islets are protected by reduction in OS at systemic levels and also within the islets in type 2 diabetes. Increased in $\beta$-cell mass, preservation of islet architecture and decreased fibrosis in the islet significantly ameliorated of the blood glucose as well as area under the curve during glucose tolerance test (GTT) in resveratrol-treated diabetic mice after 2 h., ${ }^{4,69}$

\section{Neuroprotective activity}

Resveratrol may also confer some protection on damage and toxicity against neurons due to oxidation and prevent apoptotic neuronal death which may help ameliorate neurological diseases including Alzheimer's (AD) and Parkinson's (PD) diseases. Resveratrol causes apoptosis, inhibits angiogenesis and brain tumor invasion. However, due to its limitation such as poor solubility and being chemically unstable, its bioavailability is low, thus restricting its biological and pharmacological benefits. To overcome this problem, resveratrol nanocarrier is a good choice. In order to maximize its potential as a neuroprotective agent, nanotechnology can help solve the challenge with physicochemical properties of therapeutic drugs to extend the half-life of drugs and facilitate crossing into the blood-brain barrier (BBB) ${ }^{70}$ In another study, resveratrol enhanced cognitive functions in high fat diet (HFD)fed male C67BL/6J mice by reducing serum TNF- $\alpha$ and adipose tissue's macrophage infiltration, besides diminishing neuro-inflammation and OS in the hippocampus. ${ }^{71,72}$ In the study, the experimental mice were fed with HFD alone or HFD supplemented with resveratrol for 20 weeks. Inactivation of adiponectin-mediated AMPK signaling in the HFD-fed mice hippocampus may contribute to dysregulation of brain energy and neurodegeneration, while inactivation may result in activation of GSK-3 $\beta$ and increase in Tau phosphorylation. Administration of resveratrol as well as improved diabetic control can reverse the hypoadiponectinemia and neuro-inflammation. ${ }^{71}$

A molecule that is one of the crucial elements in maintaining stable cerebral blood flow or brain-derived neurotrophic factor (BNDF), is known for its neuroprotective effects in many neurodegenerative disorders. Oral resveratrol may exert similar expression as BNDF mRNA in the hippocampus of male Sprague-Dawley rats ${ }^{73}$ pre-treated with either resveratrol (10 mg/kg administered orally for four weeks) or a placebo. Resveratrol pre-treated group had a significant surge in BDNF concentration after four weeks indicating that it has some neuroprotective effects. ${ }^{74}$ In another study, an extended 52-weeks, 
randomized, double-blind, placebo-controlled trial in human on resveratrol for the treatment of mild-to-moderate dementia due to Alzheimer's Disease (AD) was conducted. ${ }^{75}$ The safety, tolerability, concentration of biomarkers as well as clinical outcomes were assessed. Due to disease progression, cerebrospinal fluid (CSF) Abeta40 and plasma A40 levels were significantly reduced as expected in the placebo group. On the contrary, resveratrol-treated group had significantly stabilized CSF A40 and plasma A40 levels. As dementia progresses, brain pseudo-atrophy was more prominent. However, resveratrol stabilized the progressive decline seen as well as in plasma A40 and CSF A40 levels. It was concluded that resveratrol attenuates the decline in the functional measure of Alzheimer's Disease Cooperative StudyActivities of Daily Living (ADCS-ADL) ${ }^{75}$

\section{Antiviral activity}

Huang et al. ${ }^{76}$ recently assessed resveratrol's against Rotavirus (RV) using in vitro plaque reduction assays. Results of the study indicated that resveratrol $(20 \mu \mathrm{M})$ significantly inhibited RV replication in Caco2 cell lines. Using a model of RV-infected suckling mice, they found that resveratrol administration (10 and $20 \mathrm{mg} / \mathrm{kg}$, p.o., for five days) significantly reduced the severity of diarrhoea, lowered viral titers and relieved associated symptoms. In mice treated with resveratrol after RV infection, mRNA expression of IL-2, IL-10, TNF- $\alpha$, IF- $\alpha$, macrophage inflammatory protein 1 and monocyte chemotactic protein-1 was significantly reduced in the intestinal tissue. ${ }^{76}$ Resveratrol's antiviral action mechanisms have been identified in multiple studies by inhibiting viral protein synthesis, inhibiting various transcription and signalling pathways, and inhibiting viral gene expression. ${ }^{77}$ Resveratrol was found to be an effective suppressor of respiratory syncytial virus (RSV) infections, inflammation and the airway hyper-responsiveness response (AHR) associated with RSV infection in a study by Zang et al. ${ }^{78}$ Resveratrol decreased the RSV lung titers and the amount of lymphocyte infiltration present in bronchoalveolar lavage fluid (BALF) and reduced inflammation. Resveratrol significantly reduced IFN- $\gamma$ levels of RSV-infected mice in BALF, and decreased methacholine responses triggered by RSV infection. The resveratrol's antiviral activity also regulated the expression of a "Toll-like receptor 3 (TLR3), inhibited the TRIF signalling pathway and induced M2 receptor expression following RSV infection" ${ }^{37,78}$

In other study, derivatives of resveratrol have been used to be tested for anti-HIV-1 activity and their capability to increase the activity of antiviral of decitabine. The viral replication was decreased by increasing the HIV-1 mutation rate. The data showed six derivatives of resveratrol have anti-HIV-1 activity which is greater than resveratrol itself. However, resveratrol was the only compound that could be combined with decitabine to act synergistically in inhibiting HIV-1 infectivity due to their ability to potentiate cellular toxicity. It has been revealed that novel resveratrol derivatives with anti-HIV-1 activity could be used as it believed to have a different mechanism of action from the current HIV-1 drugs. ${ }^{77,79}$ In search of novel antiviral, resveratrol, a natural polyphenol, has shown a high potential of antiviral activities and that could be investigated more in both human and animal viral infections.

\section{Anti-obesity}

Some polyphenols, a class of natural bioactive, including resveratrol, quercetin and curcumin, have a potential benefits function in treating obesity. There is experimental yet limited clinical evidence that supports their anti-obesity activity that was mainly affecting the adipose tissue. Resveratrol reduce intracellular OS, inhibiting lipogenesis, adipogenesis and chronic inflammation, and suppressing preadipocyte differentiation to mature adipocytes. Currently, several ongoing clinical studies investigate the effects of resveratrol, but none of them was designed to test the weight change of obese subjects treated with resveratrol..$^{80} \mathrm{~A}$ analysis on the anti-obesity activity of resveratrol done by Zhao et al. ${ }^{80}$ stated that adipogenesis could be inhibited by reducing the stability and transcriptional activity of peroxisome proliferator-activated receptor (PPAR) $\gamma$. Floyd et al. ${ }^{81}$ suggested resveratrol could have a novel mechanism of action as it modulates PPAR $\gamma$ protein levels in 3T3-L1 adipocytes by inhibition of PPAR $\gamma$ gene expression associated with repression of PPAR $\gamma$ transcriptional activity, coupled with increased ubiquitin-proteasome-dependent degradation of $\operatorname{PPAR} \gamma$ proteins. PPAR $\gamma$ was important for the formation and function of adipocytes besides involve in regulating insulin sensitivity. Thus, it indicates that changes of insulin-dependent in glucose uptake and glycogen levels was inhibited by resveratrol. Additionally, it also decreased the insulin receptor substrate 1 as well as the level of glucose transporter 4 protein. ${ }^{81}$ In another study, resveratrol was believed to have prevented the accumulation of triglyceride by amplifying the expression of SIRT1 which was a significant molecular target regulating cellular energy metabolism and mitochondrial homeostasis ${ }^{80}$ The reduction of TG accumulation was abolished by inhibition of SIRT-1 and PGC1a. The inhibition of SIRT-1 enhanced genes expressions that involved in FFA uptake (PPAR $\gamma$ and lipoprotein lipase]) and $\beta$-oxidation regulation [PGC1- $\alpha$ and carnitine palmitoyl-transferase $1 \mathrm{a}(\mathrm{CPT} 1 \mathrm{a})] .^{82}$

\section{Cardioprotection}

Research for substances to improve cardiovascular problem has gained into interest. Resveratrol is one of the polyphenolic compounds that believed to exert beneficial effects on several cardiovascular-related diseases including hypertension, obesity, inflammation, diabetes and dyslipidaemia, as well as establish a pharmacological approach towards metabolic syndrome treatment, which is associated with an increased risk of cardiovascular disease development. ${ }^{83}$ There was a study on influences of red wine polyphenols on the regulation of endothelial nitric oxide synthase (eNOS) expression, following synthesis of endothelial NO, a pivotal vasoprotective molecule. It revealed that an alcohol-free red wine polyphenol extract increased the eNOS expression and subsequent endothelial NO release. The high level of active eNOS may interrupt the development of endothelial dysfunction and atherosclerosis. ${ }^{83,84}$ The effects of resveratrol on high blood pressure and prevention of adaptive cardiac hypertrophy was conducted by Dolinsky et al. ${ }^{85}$ and found that resveratrol prevented rises in systolic blood pressure. It improved vascular function, decreased serum and cardiac levels of the lipid peroxidation by-product, 4-hydroxy2-nonenal in the spontaneously hypertensive rat (SHRs) as well as inhibiting the superoxide production in endothelial cells derived from human. Resveratrol enhanced the LKB1/adenosine monophosphate (AMP)-activated protein kinase (AMPK) signal transduction pathway, thus increase the endothelial NO synthase (eNOS) phosphorylation. It also reduced the hypertrophic myocardium by reducing haemodynamic load and inhibition of the p70 S6 kinase pro-hypertrophic signaling cascade $^{83,85}$ Adverse cardiac remodelling and dysfunction could happen due to pressure overload (PO) of the heart and this progresses to heart failure. A study showed resveratrol has potent cardioprotective activities against TAC-induced heart failure in the C57/BL6 mouse that was mediated by the inhibition of OS and inflammation in preventing the progression of heart failure..$^{83,86}$

Resveratrol possessed cardioprotective effects on myocardial ischemic rats by improving ventricular recovery and reduced infarct size as well as cardiomyocyte apoptosis. "Resveratrol preconditions (PC) the heart through activation of adenosine $\mathrm{A} 1$ and $\mathrm{A} 3$ receptors, the former transmitting a survival signal through PI3-kinase-Akt-Bcl-2 signaling pathway and the later protecting the heart through a CREB-dependent Bcl-2 pathway in addition to an Akt-Bcl-2 pathway". ${ }^{83,87}$ Göçmen et al. ${ }^{88}$ investigated the role of resveratrol in affecting CD40 ligand (CD40L) and its receptor CD40 in platelets of hypercholesterolemia. The results showed resveratrol reduced the increase of lipids, sCD40 and IL-6 in hypercholesterolemia as well as downregulated the platelet P-selectin, CD40 and CD40L expressions. ${ }^{83,88}$ 


\section{Antioxidant activity}

Chatterjee et al. ${ }^{89}$ showed that resveratrol analogues exert antioxidant activity on breast cancer. Resveratrol analogues increased level of mRNA, attenuated oxidative DNA damage, scavenged cellular ROS production, increased level of protein expression of superoxide dismutase 3 (SOD3) and NQO1 and activated Nrf-2 signaling pathway, thus prevents the development of breast cancer. Resveratrol possesses an antioxidant activity due to the presence of three hydroxyl groups in positions 3, 4' and 5 and presence of aromatic rings and a double bond in the molecule. ${ }^{90} \mathrm{~A}$ study investigated the activity towards hydroxyl $(\bullet \mathrm{OH})$ and hydroperoxyl $(\bullet \mathrm{OOH})$ radicals indicated that trans-resveratrol reacts with $\bullet \mathrm{OH}$ radicals very efficiently, regardless of the reaction pathway. It showed that trans-resveratrol is unselective yet effective $\cdot \mathrm{OH}$ radical scavenger that provides antioxidant protection to the cell..$^{90,91}$

\section{Anti-aging activity}

In recent years, numerous studies have been done on resveratrol as it is disclosed to be a strong antioxidant, a genetic expression modulator via signal transduction, inhibitor of inflammatory mediators and phyto-hormonal effects. The biological properties and impact on cosmetic make resveratrol to be established as an anti-aging product. Mitochondrial dysfunction is believed relatable to the aging process. Maintaining the function of mitochondrial could prevent aging. Resveratrol exhibits anti-aging properties, yet the mechanism of action is still unclear. Wang et al. ${ }^{92}$ demonstrated the anti-aging activity of resveratrol on zebrafish retina as a model for age-related oculopathy. It showed that mitochondrial dysfunction and increased Akt/mTOR activity were the cause of aging. Treatment of resveratrol promoted mitochondrial function, upregulating AMPK/SIRT-1/PGC1- $\alpha$ and down-regulated Akt/mTOR pathway activity in zebrafish retinas indicated that resveratrol could be used as novel anti-aging supplements. ${ }^{92}$ Another research used D-galactose (D-gal) induced rats as an aging animal model. Treatment of resveratrol against OS by increasing the activity of the antioxidant enzymes, reducing the LPO products levels and maintain the balance of oxidative and antioxidative systems. Resveratrol inhibits AAPH-induced senescence and apoptosis as well as reverse $\mathrm{D}$-gal-induced cognitive impairment and telomerase (TE) activity. It up-regulates TE activity, decreasing oxidative damage, regulating SIRT-1 pathway. From the data, more robust anti-aging properties is shown by resveratrol $(10 \mu \mathrm{M})$ in vitro and high dose $(100$ $\mathrm{mg} / \mathrm{kg}$, p.o. for 6 weeks) in vivo. ${ }^{93}$ Another study reported that the antioxidant activity of resveratrol is 17 times greater than idebenone when used in skincare formulation. Thus, prevention of photo-aging by resveratrol has been reviewed and compared with other antioxidants. ${ }^{94}$

\section{Nephroprotection}

A study confirmed the protective effects of resveratrol in uremic rat kidney by investigating the expression of heat shock protein 70 (HSP70). ${ }^{73}$ Sprague Dawley rats were classified into five different groups which were sham, uremic and resveratrol (5, 10 and $20 \mathrm{mg} /$ $\mathrm{kg}$ ). Serum creatinine (Cr) and blood urea nitrogen (BUN) levels as well as renal interstitial collagen deposition were significantly increased in all groups. Resveratrol groups when administered in different doses decreased the levels of $\mathrm{Cr}$ and BUN with amelioration of renal interstitial collagen deposition. Additionally, there was improved renal tissue lesions in resveratrol-treated group as compared to other groups. ${ }^{73}$ There was also an increase in HSP70 and p-IкB $\alpha$ expression and decrease in $\mathrm{p}-65$ protein level in renal tissues, for all administered resveratrol doses. Following the addition of MKT-077 (a cationic rhodacyanine dye analogue used for preclinical cancer trials due to its selective toxic effects on cancer cells) there were remarkable reduction in HSP70 and p-IкBa levels in renal tissues of resveratrol-treated group with increased levels of p-P65 protein. ${ }^{73}$ Overall, the findings indicate that resveratrol play a positive role in the kidney of uremic rats by activating HSP70 expression. ${ }^{73}$ In a study conducted on female Sprague Dawley rats ${ }^{95}$, there was increased total antioxidant status, decreased Cr, BUN, OS-index and total oxidant status as well as reduced weight gain following resveratrol treatment for 15 days. It was concluded that the side effects of risperidone on kidney tissues can be prevented with resveratrol which has a kidney protective effect. ${ }^{95}$

\section{SAFETY, TOLERABILITY AND TOXICITY OF RESVERATROL}

In all of the reviewed human studies, generally, resveratrol is welltolerated. A 29-day human study showed that high dose resveratrol (2.5 - $5.0 \mathrm{~g}$ ) can cause gastrointestinal discomfort as well as spontaneously resolving diarrhea. ${ }^{96}$ In a survey consisting of eight healthy subjects administered with trans-resveratrol (2000 $\mathrm{mg}$, two times in a day), although generally it was well tolerated, diarrhea was the only side effect observed. ${ }^{33}$ In another study, Almeida et al. ${ }^{97}$ indicated that nine out of the 18 adverse events (AEs) were possibly related to resveratrol treatment with four subjects from the $25 \mathrm{mg}$ group, one each from the $50 \mathrm{mg}$ and $100 \mathrm{mg}$ trans-resveratrol groups and two from the $150 \mathrm{mg}$ group. The most frequent symptom was frontal headache with three subjects were observed from each group. Besides that, headache, muscle ache of lower extremities, lethargy, epididymitis, dizziness and occipital headache were observed (once each). The AEs were deemed as mild in severity and do not cause any deaths, serious AEs or discontinuations. ${ }^{97}$ A Phase I oral resveratrol analysis (single dose of $0.5,1,2.5$, or $5 \mathrm{~g}$ ) was performed on 10 healthy volunteers per dose level. Results showed that resveratrol consumption was not causing major AEs. ${ }^{29}$ In animal models, toxic doses produce physiopathological processes in the kidney. ${ }^{98,99}$ A three month study on rats showed resveratrol has a low order of toxicity and there was no AEs on the mortality rate. ${ }^{99}$

\section{APPLICATIONS OF RESVERATROL FOR FOOD AND COSMETIC PURPOSES}

Resveratrol's good therapeutic benefits, cost-effectiveness and the prospect of conferring fewer adverse effects have posed interest from the food community. The extracted and isolated resveratrol has a broad range of biological activities including anticancer, cardioprotective effects, neuroprotective activity, antioxidant and anti-inflammatory effects make it a potential compound further research for drug development. ${ }^{100-103}$ Besides, different oligomers of resveratrol were confirmed to possess a wide range of properties, including antibacterial, antifungal and antiviral activities. ${ }^{11}$ The anti-aging properties, as well as other pharmacological activities of resveratrol, make it a promising element that can be developed by the food and supplements industry as well as to be established as cosmetics products. Moreover, for a wider range of potentiality in the food industry, reaction with other chemicals to form new derivatives can be done. ${ }^{104}$

\section{DISCUSSION}

To date, many studies have confirmed that resveratrol is a natural polyphenol found in various sources especially in dietary sources including grapes, peanuts and berries. ${ }^{21}$ The wide range of its biological properties has expanded interests on in-depth investigations on its medicinal benefits. Despite its wide range of bioactive uses, resveratrol has low bioavailability and is extensively metabolised. ${ }^{29}$ Following only a few hours of administration, resveratrol concentration in the urine is relatively high, reflecting its rapid absorption; in contrast to the low concentration of the parent compound found in the plasma. ${ }^{31,105}$ Thus, this challenge has attracted several researchers to investigate on enhancement of its bioavailability. ${ }^{36-38}$ On the other hand, clinical trials need to base on in vitro studies to determine the right concentration. 
The investigated concentration may reflect the scenario for clinical use and must be able to target the right pathway to exert the expected outcome. Commonly used resveratrol concentrations are in the range of millimole per litre (parent compound) or $\mathrm{nmol} / \mathrm{l}$ concentrations (metabolites). A higher dose is normally utilised to yield the expected outcome although these results should be cautiously analyzed and interpreted. ${ }^{9}$ In this review, the chemistry, bioavailability and recently reported biological properties of resveratrol were highlighted. Overall, resveratrol's wide therapeutic applicability as anticancer, analgesic, anti-inflammatory, antidiabetic, nephroprotective, neuroprotective, antiviral, anti-obesity, cardioprotective effects, antioxidant and antiaging effects make it a substance of interest for clinical research in the future. Additionally, future research needs to focus more on investigation of its physicochemical properties and formulation that can enhance its bioavailability that can be confirmed in clinical studies.

\section{CONCLUSION AND FUTURE PERSPECTIVES}

Currently, the use of natural products and its derived compounds are gaining universal impressive popularity as opposed to conventional/ modern medicines for the treatment of numerous disorders owing to low cost and less toxic effects. Abundant experimental confirmations indicate that these phytonutrients are proficient of treating numerous diseases and pathological conditions including diabetes, cognitive disabilities, depression, anxiety, inflammation, hypertension, hepatic disorders, asthma, pain, cancer, and skin diseases. Resveratrol is a polyphenol which is not flavonoid and belongs to stilbenes. The efficacy of resveratrol in pathological conditions has been shown in a great number of studies. In this review, we have highlighted chemistry, pharmacological properties and therapeutic potential of resveratrol and it is proved to possess remarkable health benefits. Resveratrol modulates multiple molecular targets by modifying their signaling pathways, gene expression, or via direct interactions. Resveratrol regulates the expression of pro- and anti-inflammatory cytokines (IL-2, IL-6, IL-10, and TNF- $\alpha$ ), kinases (MAPK, AMPK, PI3K/Akt, m-TOR, and GSK$3 \beta$ ), growth factor (BDNF), enzymes (COX-2 and SIRT-1), apoptotic proteins (Caspase-3, Bcl-2, p38, Bax, and p65) and receptors (PPAR- $\gamma$, Tau, and TLR-3). In different pathological settings, resveratrol also modulates the function of NF- $\mathrm{KB}, \mathrm{Nrf}-2$ and its signaling pathways. The review found that resveratrol has capability to affect the numerous targets, and due to that it has the potential for the prevention and treatments for several diseases including cancer, diabetes, kidney disorders, inflammation, neurodegenerative disorders, obesity, cardiac related disorders, aging and also some of viral infections. However, despite all the potential, resveratrol has a low bioavailability. Current researches are emphasized on this particular matter by developing many derivatives of resveratrol as well as new formulations to overcome this problem. Further clinical trials are warranted in the future in order to validate its therapeutic effectiveness and use in phytopharmaceuticals as well as in food supplements.

\section{ACKNOWLEDGMENT}

The authors wish to thank the Universiti Kuala Lumpur Royal College of Medicine Perak, Malaysia for providing the facilities and services required to complete the study.

\section{CONFLICTS OF INTEREST}

The authors have no conflict of interest.

\section{ABBREVIATIONS}

•OH, Hydroxyl Radicals; •OOH, Hydroperoxyl Radicals; PTP1B, Protein tyrosine phosphatase 1B;5'-Nuc, 5'-nucleotidase; ACP, Acid phosphatase; $\mathrm{AD}$, Alzheimer disease; ADCS-ADL, Alzheimer's Disease Cooperative
Study-Activities of Daily Living; ADP-ribose, Adenosine diphosphate ribose; AE, Adverse Event; AHR, Airway Hyperresponsiveness; ALP, Alkaline Phosphatase; ALT, Aminotransferase; AMPK, Adenosine monophosphate-activated protein kinase; AOM, Azoxymethane; AST, Aspartate Aminotransferase; BALF, Bronchoalveolar Lavage Fluid; Bax, Bcl-2-associated X protein; BBB, Blood-Brain Barrier; Bcl-2, B-cell lymphoma 2; BNDF, Brain-Derived Neurotrophic Factor; BUN, Blood Urea Nitrogen; COX-1, Cyclo-oxgenase; CPT1a, Carnitine Palmitoyl-Transferase 1a; Cr, Creatinine; CREB, Camp Response Element-Binding Protein; CSC, Cancer Stem Cells; CSF, Cerebrospinal Fluid; DEN, N-nitrosodiethylamine; D-gal, D-galactose; DMBA, Dimethylbenz(a)anthracene; DNA, Deoxyribonucleic Acid; DSS, Dextran Sulfate Sodium; EEF1A2, Eukaryotic Translation Elongation Factor 1 Alpha 2; eNOS, Endothelial Nitric Oxide Synthase; GLUT4, Glucose Transporter Type 4; GSK-3 $\beta$, Glycogen Synthase Kinase 3-Beta; GTT, Glucose Tolerance Test; H\&E, Hematoxylin and Eosin stain; HCC, Hepatocellular Carcinoma; HFD, High Fat Diet; HIV-1, Human Immunodeficiency Virus 1; HNSCC, Head and Neck Squamous Cell Carcinoma; HPbCD, 2-hydroxypropyl-b-cyclodextrin; HPLC, High-Performance Liquid Chromatography; HSP70, Heat Shock Protein 70; HUVEC, Human Umbilical Vein Endothelial Cells; IFN- $\gamma$, Interferon Gamma; IL, Interleukin; IRS-2, Insulin receptor substrate-2; LDH, Lactate Dehydrogenase; LLC, Lewis Lung Carcinoma; MAPK, Mitogen-Activated Protein Kinases; MDA, Malondialdehyde; mRNA, Messenger RNA; m-TOR, Mammalian Target of Rapamycin; NF-кB, Nuclear Factor-kappa B; NO, Nitic Oxide; NQO1, NAD(P)H Quinone Dehydrogenase 1; Nrf-2, Nuclear factor erythroid 2-related factor 2; OPL, Oral Pre-neoplastic Lesion; OS, Oxidative stress; OSCC, Oral Squamous Cell Carcinoma; PanIN, Pancreatic intraepithelial neoplasia; PARP, Poly (ADP-ribose) polymerase ; PC, Preconditions; PCSCs, Pancreatic Cancer Stem Cells; PD, Parkinson's Disease; PGC1- $\alpha$, Peroxisome Proliferator-Activated Receptor Gamma Coactivator 1-Alpha; PI3K/Akt, Phosphatidylinositol 3-Kinase/Protein Kinase B; PO, Pressure Overload; PPAR- $\gamma$, Peroxisome Proliferator-Activated Receptor; RSV, Respiratory Syncytial Virus; RV, Rotavirus; RWPE, Red Wine Polyphenol Extract; SHRs, Spontaneously Hypertensive Rat ; SIRT-1, Sirtuin1; SOD3, Superoxide Dismutase 3; STZ, Streptozotocin; TCM, Traditional Chinese Medicine; TE, Telomerase; TG, Triglyceride; TLR3, Toll-Like Receptor 3; TNF- $\alpha$, Tumor Necrosis Factor Alpha; TP, Total Protein; TPA, 12-O-Tetradecanoylphorbol 13-Acetate; TRAMP, Transgenic Adenocarcinoma of the Mouse Prostate; TRIF, TIR-Domain-Containing Adapter-Inducing Interferon- $\beta$; T-SOD, Superoxide Dismutase; UV, Ultraviolet; XIAP, X-Linked Inhibitor of Apoptosis Protein; $\gamma$-GT, $\gamma$-Glutamyl Transpeptidase.

\section{REFERENCES}

1. Isha T. Stress and defense responses in plant secondary metabolites production. Biol Res. 2019;52:39.

2. Varoni EM, Lo faro AF, Sharifi-Rad J, Iriti M. Anticancer molecular mechanisms of resveratrol. Front Nutr. 2016;3:8.

3. Berman AY, Motechin RA, Wiesenfeld MY, Holz MK. The therapeutic potential of resveratrol: a review of clinical trials. NPJ Precis Oncol. 2017;1:35.

4. Oyenihi OR, Oyenihi AB, Adeyanju AA, Oguntibeju OO. Antidiabetic effects of resveratrol: the way forward in its clinical utility. J Diabet Res. 2016;2016:9737483.

5. Catalogna G, Moraca F, D'Antona L, Dattilo V, Perrotti G, Lupia A, et al. Review about the multi-target profile of resveratrol and its implication in the SGK1 inhibition. Eur J Med Chem. 2019;183:111675.

6. Wang DG, Liu WY, Chen GT. A simple method for the isolation and purification of resveratrol from Polygonum cuspidatum. J Pharm Anal. 2013;3:241-7.

7. Averilla JN, Oh J, Wu Z, Liu KH, Jang CH, Kim HJ, et al. Improved extraction of resveratrol and antioxidants from grape peel using heat and enzymatic treatments. J Sci Food Agric. 2019;99:4043-53

8. Harikumar KB, Aggarwal BB. Resveratrol: A multitargeted agent for ageassociated chronic diseases. Cell Cycle. 2008;7:1020-35.

9. Catalgol B, Batirel S, Taga Y, Ozer N. Resveratrol: French paradox revisited. Front Pharmacol. 2012;3:141 
10. Renaud S, de Lorgeril M. Wine, alcohol, platelets, and the French paradox for coronary heart disease. The Lancet. 1992;339:1523-26.

11. Venugopal R, Liu RH. Phytochemicals in diets for breast cancer prevention: The importance of resveratrol and ursolic acid. Food Sci Human Wellness. 2012;1:1-13

12. Vestergaard $M$, Ingmer $H$. Antibacterial and antifungal properties of resveratrol. Int J Antimicrob Agents. 2019;53:716-23.

13. Zhang H, Li C, Kwok S-T, Zhang OW, Chan SW. A review of the pharmacological effects of the dried root of Polygonum cuspidatum (Hu Zhang) and its constituents. Evid-Based Complement Alternat Med. 2013;2013:208349.

14. Acuña-Avila PE, Vásquez-Murrieta MS, Hernández MOF, Del Socorro LópezCortéz M. Relationship between the elemental composition of grapeyards and bioactive compounds in the Cabernet Sauvignon grapes Vitis vinifera harvested in Mexico. Food Chem. 2016;203:79-85.

15. Jennifer B, Takao Y, Hiroshi A, Lean M, Alan C. Plant foods and herbal sources of resveratrol. J Agric Food Chem. 2002;50:3337-40.

16. Zhang $Q$, Bian Y, ShiY, Zheng S, GuX, Zhang D, et al. An economical and efficient technology for the extraction of resveratrol from peanut (Arachis hypogaea) sprouts by multi-stage countercurrent extraction. Food Chem. 2015;179:15-25.

17. Hurst WJ, Glinski JA, Miller KB, Apgar J, Davey MH, Stuart DA. Survey of the trans-resveratrol and trans-piceid content of cocoa-containing and chocolate products. J Agric Food Chem. 2008;56:8374-8.

18. Lyons MM, Yu C, Toma R, Cho SY, Reiboldt W, Lee J, et al. Resveratrol in raw and baked blueberries and bilberries. J Agric Food Chem. 2003;51:5867-70.

19. Romero-Pérez Al, Ibern-Gómez M, Lamuela-Raventós RM, De la Torre-Boronat MC. Piceid, the major resveratrol derivative in grape juices. Journal of Agric Food Chem. 1999;47:1533-6.

20. Romero-Pérez Al, Lamuela-Raventós RM, Waterhouse AL, De La Torre-Boronat M. Levels of cis-and trans-resveratrol and their glucosides in white and rose Vitis vinifera wines from Spain. J Agric Food Chem. 1996;44:2124-8.

21. Chedea VS, Vicaș SI, Sticozzi C, Pessina F, Frosini M, Maioli E, et al. Resveratrol: from diet to topical usage. Food Funct. 2017;8:3879-92.

22. Wang F, Chatterjee S. Dominant carbons in trans- and cis-resveratrol isomerization. J Phys Chem B. 2017;121:4745-55

23. McAndrew RP, Sathitsuksanoh N, Mbughuni MM, Heins RA, Pereira JH, George $A$, et al. Structure and mechanism of NOV1, a resveratrol-cleaving dioxygenase. Proc Natl Acad Sci U S A. 2016;113:14324-9.

24. López-Hernández J, Paseiro-Losada P, Sanches-Silva AT, Lage-Yusty MA. Study of the changes of trans-resveratrol caused by ultraviolet light and determination of trans-and cis-resveratrol in Spanish white wines. Eur Food Res Technol. 2007;225:789-96.

25. Moretón-Lamas E, Lago-Crespo M, Lage-Yusty M, López-Hernández J Comparison of methods for analysis of resveratrol in dietary vegetable supplements. Food Chem. 2017;224:219-23.

26. Nour $\mathrm{V}$, Trandafir I, Muntean C. Ultraviolet irradiation of trans-resveratrol and HPLC determination of trans-resveratrol and cis-resveratrol in Romanian red wines. J Chromatogr Sci. 2012;50:920-7.

27. Saldanha JF, Leal VDO, Stenvinkel P, Carraro-Eduardo JC, Mafra D. Resveratrol: why is it a promising therapy for chronic kidney disease patients? Oxid Med Cell Longev. 2013;2013:963217.

28. Burns J, Yokota T, Ashihara H, Lean ME, Crozier A. Plant foods and herbal sources of resveratrol. J Agric Food Chem. 2002;50:3337-40.

29. Boocock DJ, Faust GE, Patel KR, Schinas AM, Brown VA, Ducharme MP, et al. Phase I dose escalation pharmacokinetic study in healthy volunteers of resveratrol, a potential cancer chemopreventive agent. Cancer Epidemiol Biomarkers Prev. 2007;16:1246-52.

30. Kaldas MI, Walle UK, Walle T. Resveratrol transport and metabolism by human intestinal Caco - 2 cells. J Pharm Pharmacol. 2003;55:307-12.

31. Walle T, Hsieh F, DeLegge MH, Oatis JE, Walle UK. High absorption but very low bioavailability of oral resveratrol in humans. Drug Metab Dispos. 2004;32:1377-82.

32. Vitrac X, Desmouliere A, Brouillaud B, Krisa S, Deffieux G, Barthe N, et al. Distribution of [14C]-trans-resveratrol, a cancer chemopreventive polyphenol, in mouse tissues after oral administration. Life Sci. 2003;72:2219-33.

33. La Porte C, Voduc N, Zhang G, Seguin I, Tardiff D, Singhal N, et al. Steadystate pharmacokinetics and tolerability of trans-resveratrol $2000 \mathrm{mg}$ twice daily with food, quercetin and alcohol (ethanol) in healthy human subjects. Clin Pharmacokinet. 2010;49:449-54

34. Springer M, Moco S. Resveratrol and its human metabolites - Effects on metabolic health and obesity. Nutrients. 2019;11(1):143.

35. Yu C, Shin YG, Chow A, Li Y, Kosmeder JW, Lee YS, et al. Human, rat, and mouse metabolism of resveratrol. Pharmaceut Res. 2002;19:1907-14.

36. Amiot MJ, Romier B, Dao TMA, Fanciullino R, Ciccolini J, Burcelin R, et al. Optimization of trans-Resveratrol bioavailability for human therapy. Biochimie. 2013:95:1233-8.
37. Peñalva R, Morales J, González-Navarro CJ, Larrañeta E, Quincoces G, Peñuelas I, et al. Increased oral bioavailability of resveratrol by its encapsulation in casein nanoparticles. Int J Mol Sci. 2018;19:2816.

38. Calvo - Castro LA, Schiborr C, David F, Ehrt H, Voggel J, Sus N, et al. The oral bioavailability of trans - resveratrol from a grapevine - shoot extract in healthy humans is significantly increased by micellar solubilization. Mol Nutri Food Res. 2018;62:1701057.

39. Salehi B, Mishra AP, Nigam M, Sener B, Kilic M, Sharifi-Rad M, et al. Resveratrol: A double-edged sword in health benefits. Biomed. 2018;6:91.

40. Sergides C, Chirilă M, Silvestro L, Pitta D, Pittas A. Bioavailability and safety study of resveratrol $500 \mathrm{mg}$ tablets in healthy male and female volunteers. Exp Ther Med. 2016;11:164-70.

41. Xiao Q, ZhuW, Feng W, Lee SS, Leung AW, Shen J, et al. A review of resveratrol as a potent chemoprotective and synergistic agent in cancer chemotherapy. Front Pharmacol. 2019;9:1534.

42. Kapadia GJ, Azuine MA, Tokuda H, Takasaki M, Mukainaka T, Konoshima T, et al. Chemopreventive effect of resveratrol, sesamol, sesame oil and sunflower oil in the Epstein-Barr virus early antigen activation assay and the mouse skin two-stage carcinogenesis. Pharmacol Res. 2002;45:499-505.

43. Jang M, Cai L, Udeani GO, Slowing KV, Thomas CF, Beecher CW, et al. Cancer chemopreventive activity of resveratrol, a natural product derived from grapes. Science. 1997;275:218-20.

44. Harper CE, Patel BB, Wang J, Arabshahi A, Eltoum IA, Lamartiniere CA Resveratrol suppresses prostate cancer progression in transgenic mice. Carcinogenesis. 2007;28:1946-53.

45. Cui $X$, Jin $Y$, Hofseth AB, Pena E, Habiger J, Chumanevich A, et al. Resveratro suppresses colitis and colon cancer associated with colitis. Cancer Prev Res. 2010;3:549-59.

46. Rajasekaran D, Elavarasan J, Sivalingam M, Ganapathy E, Kumar A, Kalpana K et al. Resveratrol interferes with $\mathrm{N}$-nitrosodiethylamine-induced hepatocellular carcinoma at early and advanced stages in male Wistar rats. Mol Med Rep. 2011;4:1211-7.

47. Shankar S, Nall D, Tang SN, Meeker D, Passarini J, Sharma J, et al. Resveratrol inhibits pancreatic cancer stem cell characteristics in human and Kras G12D transgenic mice by inhibiting pluripotency maintaining factors and epithelialmesenchymal transition. PloS one. 2011;6:e16530.

48. Kimura Y, Okuda H. Resveratrol isolated from Polygonum cuspidatum root prevents tumor growth and metastasis to lung and tumor-induced neovascularization in Lewis lung carcinoma-bearing mice. J Nut. 2001;131:18449.

49. Berta GN, Salamone P, Sprio AE, Di Scipio F, Marinos LM, Sapino S, et al. Chemoprevention of 7, 12-dimethylbenz [a] anthracene (DMBA)-induced oral carcinogenesis in hamster cheek pouch by topical application of resveratrol complexed with 2-hydroxypropyl- $\beta$-cyclodextrin. Oral Oncol. 2010;46:42-8.

50. Woodall CE, Li Y, Liu OH, Wo J, Martin RC. Chemoprevention of metaplasia initiation and carcinogenic progression to esophageal adenocarcinoma by resveratrol supplementation. Anticancer Drugs. 2009;20:437-43.

51. Lee MH, Choi BY, Kundu JK, Shin YK, Na HK, Surh YJ. Resveratrol suppresses growth of human ovarian cancer cells in culture and in a murine xenograft model: eukaryotic elongation factor $1 \mathrm{~A} 2$ as a potential target. Cancer Res. 2009;69:7449-58.

52. Bai Y, Mao QQ, Qin J, Zheng XY, Wang YB, Yang K, et al. Resveratrol induces apoptosis and cell cycle arrest of human T24 bladder cancer cells in vitro and inhibits tumor growth in vivo. Cancer Sci. 2010;101:488-93.

53. Zhou HB, Chen JM, Cai JT, Du Q, Wu CN. Anticancer activity of genistein on implanted tumor of human SG7901 cells in nude mice. World J Gastroenterol. 2008; $14: 627$

54. Tyagi A, Gu M, TakahataT, Frederick B, Agarwal C, Siriwardana S, et al. Resveratrol selectively induces DNA damage, independent of Smad4 expression, in its efficacy against human head and neck squamous cell carcinoma. Clin Cancer Res. 2011;17:5402-11.

55. Chen Y, Chen JC, Tseng SH. Tetrandrine suppresses tumor growth and angiogenesis of gliomas in rats. Int J Cancer. 2009;124:2260-9.

56. Van Ginkel PR, Sareen D, Subramanian L, Walker Q, Darjatmoko SR, Lindstrom $\mathrm{MJ}$, et al. Resveratrol inhibits tumor growth of human neuroblastoma and mediates apoptosis by directly targeting mitochondria. Clin Cancer Res. 2007;13:5162-9.

57. Harikumar KB, Kunnumakkara AB, Sethi G, Diagaradjane P, Anand P, Pandey MK, et al. Resveratrol, a multitargeted agent, can enhance antitumor activity of gemcitabine in vitro and in orthotopic mouse model of human pancreatic cancer. Int J Cancer. 2010;127:257-68.

58. Ko JH, Sethi G, Um JY, Shanmugam MK, Arfuso F, Kumar AP, et al. The role of resveratrol in cancer therapy. Int J Mol Sci. 2017;18:2589.

59. Kundu JK, Surh YJ. Cancer chemopreventive and therapeutic potential of resveratrol: mechanistic perspectives. Cancer Lett. 2008;269:243-61. 
60. Udenigwe CC, Ramprasath VR, Aluko RE, Jones PJH. Potential of resveratrol in anticancer and anti-inflammatory therapy. Nutri Rev. 2008;66:445-4.

61. De Sá Coutinho D, Pacheco MT, Frozza RL, Bernardi A. Anti-inflammatory effects of resveratrol: Mechanistic insights. Int J Mol Sci. 2018;19:1812.

62. Wang G, Hu Z, Song X, Cui Q, Fu Q, Jia R, et al. Analgesic and anti-inflammatory activities of resveratrol through classic models in mice and rats. Evid-Based Complement Altern Med. 2017;2017:5197567.

63. Nanjan MJ, Betz J. Resveratrol for the management of diabetes and its downstream pathologies. Eur Endocrinol. 2014;10:31.

64. Movahed A, Nabipour I, Lieben Louis X, Thandapilly SJ, Yu L, Kalantarhormozi $\mathrm{M}$, et al. Antihyperglycemic effects of short term resveratrol supplementation in type 2 diabetic patients. Evid-Based Complementary Alternat Med. 2013;2013:851267.

65. Dash S, Xiao C, Morgantini C, Szeto L, Lewis GF. High-dose resveratrol treatment for 2 weeks inhibits intestinal and hepatic lipoprotein production in overweight/obese men. Arterioscler Thromb Vasc Biol. 2013;33:2895-901.

66. Knop F, Konings E, Timmers S, Schrauwen P, Holst JJ, Blaak E. Thirty days of resveratrol supplementation does not affect postprandial incretin hormone responses, but suppresses postprandial glucagon in obese subjects. Diabetic Med. 2013;30:1214-8.

67. Bashmakov YK, Assaad-Khalil SH, Abou Seif M, Udumyan R, Megallaa M Rohoma $\mathrm{KH}$, et al. Resveratrol promotes foot ulcer size reduction in type 2 diabetes patients. ISRN Endocrinol. 2014;2014:816307.

68. González-Rodríguez Á, Santamaría B, Mas-Gutierrez JA, Rada P, Fernández - Millán E, Pardo $V$, et al. Resveratrol treatment restores peripheral insulin sensitivity in diabetic mice in a sirt1 - independent manner. Mol Nutr Food Res. 2015;59:1431-42.

69. Lee YE, Kim JW, Lee EM, Ahn YB, Song KH, Yoon KH, et al. Chronic resveratrol treatment protects pancreatic islets against oxidative stress in $\mathrm{db} / \mathrm{db}$ mice. PLoS One. 2012;7:e50412.

70. Andrade S, Ramalho MJ, Pereira MdC, Loureiro JA. Resveratrol brain delivery for neurological disorders prevention and treatment. Front Pharmacol. 2018;9:1261.

71. Jeon BT, Jeong EA, Shin HJ, LeeY, Lee DH, Kim HJ, et al. Resveratrol attenuates obesity-associated peripheral and central inflammation and improves memory deficit in mice fed a high-fat diet. Diabetes. 2012;61:1444-54.

72. Liang J, Tian S, Han J, Xiong P. Resveratrol as a therapeutic agent for renal fibrosis induced by unilateral ureteral obstruction. Ren Fail. 2014;36:285-91.

73. Feng S, Wang J, Teng J, Fang Z, Lin C. Resveratrol plays protective roles on kidney of uremic rats via activating HSP70 expression. BioMed Res Int. 2020;2020:2126748.

74. Wiciński M, Malinowski B, Węclewicz MM, Grześk E, Grześk G. Resveratrol increases serum BDNF concentrations and reduces vascular smooth muscle cells contractility via a NOS-3-independent mechanism. BioMed Res Int. 2017;2017:9202954.

75. Sawda C, Moussa C, Turner RS. Resveratrol for Alzheimer's disease. Ann NY Acad Sci. 2017;1403:142.

76. Huang H, Liao D, Zhou G, Zhu Z, Cui Y, Pu R. Antiviral activities of resveratrol against rotavirus in vitro and in vivo. Phytomedicine. 2020:153230.

77. Abba $Y$, Hassim H, Hamzah H, Noordin MM. Antiviral activity of resveratrol against human and animal viruses. Adv Virol. 2015;2015:184241

78. Zang N, Xie X, Deng Y, Wu S, Wang L, Peng C, et al. Resveratrolmediated gamma interferon reduction prevents airway inflammation and airway hyperresponsiveness in respiratory syncytial virus-infected immunocompromised mice. J Virol. 2011;85:13061-8.

79. Clouser CL, Chauhan J, Bess MA, Van Oploo JL, Zhou D, Dimick-Gray S, et al. Anti-HIV-1 activity of resveratrol derivatives and synergistic inhibition of HIV1 by the combination of resveratrol and decitabine. Bioorg. Med Chem Lett. 2012;22:6642-6.

80. Zhao Y, Chen B, Shen J, Wan L, Zhu Y, Yi T, et al. The beneficial effects of quercetin, curcumin, and resveratrol in obesity. Oxid Med Cell Longev. 2017;2017:1459497.

81. Floyd ZE, Wang ZQ, Kilroy G, Cefalu WT. Modulation of peroxisome PPAR- $\gamma$ stability and transcriptional activity in adipocytes by resveratrol. Metabolism. 2008;57:S32-S38.

82. Imamura H, Nagayama D, Ishihara N, Tanaka S, Watanabe R, Watanabe $Y$, et al. Resveratrol attenuates triglyceride accumulation associated with upregulation of Sirt1 and lipoprotein lipase in 3T3-L1 adipocytes. Mol Genet Metab Rep. 2017; 12:44-50.

83. Bonnefont-Rousselot D. Resveratrol and cardiovascular diseases. Nutrients. 2016;8:250.
84. Leikert JF, Rathel TR, Wohlfart P, Cheynier V, Vollmar AM, Dirsch VM. Red wine polyphenols enhance endothelial nitric oxide synthase expression and subsequent nitric oxide release from endothelial cells. Circulation. 2002;106:1614-7.

85. Dolinsky VW, Chakrabarti S, Pereira TJ, Oka T, Levasseur J, Beker D, et al. Resveratrol prevents hypertension and cardiac hypertrophy in hypertensive rats and mice. Biochim Biophy Acta. 2013;1832:1723-33.

86. Gupta PK, DiPette DJ, Supowit SC. Protective effect of resveratrol against pressure overload - induced heart failure. Food Sci Nutr. 2014;2:218-29.

87. Das S, Cordis GA, Maulik N, Das DK. Pharmacological preconditioning with resveratrol: role of CREB-dependent $\mathrm{Bcl}-2$ signaling via adenosine $\mathrm{A} 3$ receptor activation. American J Physiol-Heart and Circulat Physiol. 2005;288:H328-H335.

88. Göçmen AY, Burgucu D, Gümüşlü S. Effect of resveratrol on platelet activation in hypercholesterolemic rats: CD40-CD40L system as a potential target. Appl Physio Nutr Metab. 2011;36:323-30.

89. Chatterjee A, Ronghe A, Padhye SB, Spade DA, Bhat NK, Bhat HK. Antioxidant activities of novel resveratrol analogs in breast cancer. J Biochem Molecul Toxicol. 2018;32:e21925.

90. Gerszon J, Rodacka A, Puchała M. Antioxidant properties of resveratrol and its protective effects in neurodegenerative diseases. Med J Cell Biol. 2014;4:97117.

91. Iuga C, Alvarez-Idaboy JR, Russo N. Antioxidant activity of trans-resveratrol toward hydroxyl and hydroperoxyl radicals: a quantum chemical and computational kinetics study. J Org Chem. 2012;77:3868-77.

92. Wang N, Luo Z, Jin M, Sheng W, Wang HT, Long X, et al. Exploration of agerelated mitochondrial dysfunction and the anti-aging effects of resveratrol in zebrafish retina. Aging. 2019;11:3117.

93. Li J, Zhang CX, Liu YM, Chen KL, Chen G. A comparative study of anti-aging properties and mechanism: resveratrol and caloric restriction. Oncotarget. 2017;8:65717.

94. Baxter RA. Anti-aging properties of resveratrol: review and report of a potent new antioxidant skin care formulation. J Cosmet Dermatol. 2008;7:2-7.

95. Bilgiç S, Korkmaz DT, Azirak S, Güvenç AN, Kocaman N, Özer MK. Risperidoneinduced renal damage and metabolic side effects: The protective effect of resveratrol. Oxid Med Cell Longev. 2017;2017:8709521.

96. Brown VA, Patel KR, Viskaduraki M, Crowell JA, Perloff M, Booth TD, et al. Repeat dose study of the cancer chemopreventive agent resveratrol in healthy volunteers: Safety, pharmacokinetics and effect on the insulin-like growth factor axis. Cancer Res. 2010;70:9003-11.

97. Almeida L, Vaz - da - Silva M, Falcão A, Soares E, Costa R, Loureiro Al, et al Pharmacokinetic and safety profile of trans - resveratrol in a rising multiple dose study in healthy volunteers. Mol Nutr Food Res. 2009;53:S7-S15.

98. Tomé-Carneiro J, Gonzálvez M, Larrosa M, Yáñez-Gascón MJ, García-Almagro FJ, Ruiz-Ros JA, et al. One-year consumption of a grape nutraceutical containing resveratrol improves the inflammatory and fibrinolytic status of patients in primary prevention of cardiovascular disease. The American $\mathrm{J}$ Cardio. 2012;110:356-63.

99. Williams LD, Burdock GA, Edwards JA, Beck M, Bausch J. Safety studies conducted on high-purity trans-resveratrol in experimental animals. Food Chem Toxicol. 2009;47:2170-82.

100. Al-Qahtani AA, Osman AM, Al-Kreathy HM, Al-Harthy SE, Al-Malky HS, AlNasser MS, et al. Chemosensitizing effects of marine Astaxanthin on the anti-cancer activity of doxorubicin in tumor bearing mice. Int $\mathrm{J}$ Cancer Res. 2019;15:1-8.

101. De Oliveira MR, Chenet AL, Duarte AR, Scaini G, Quevedo J. Molecular mechanisms underlying the anti-depressant effects of resveratrol: a review. Mol Neurobiol. 2018;55:4543-59.

102. Luca SV, Macovei I, Bujor A, Miron A, Skalicka-Woźniak K, Aprotosoaie AC, et al. Bioactivity of dietary polyphenols: The role of metabolites. Crit Rev Food Sci Nutr. 2020;60:626-59.

103. Ratz-tyko A, Arct J. Resveratrol as an active ingredient for cosmetic and dermatological applications: A review. J Cosmet Laser Ther. 2019;21:84-90.

104. Oh WY, Shahidi F. Antioxidant activity of resveratrol ester derivatives in food and biological model systems. Food Chem. 2018;261:267-73.

105. Lee EO, Lee HJ, Hwang HS, Ahn KS, Chae C, Kang KS, et al. Potent inhibition of Lewis lung cancer growth by heyneanol A from the roots of Vitis amurensis through apoptotic and anti-angiogenic activities. Carcinogenesis. 2006;27:2059-69.

106. González-Rodríguez Á, Gutierrez JAM, Sanz-González S, Ros M, Burks DJ Valverde ÁM. Inhibition of PTP1B restores IRS1-mediated hepatic insulin signaling in IRS2-deficient mice. Diabetes. 2010;59:588-99. 


\section{GRAPHICAL ABSTRACT}

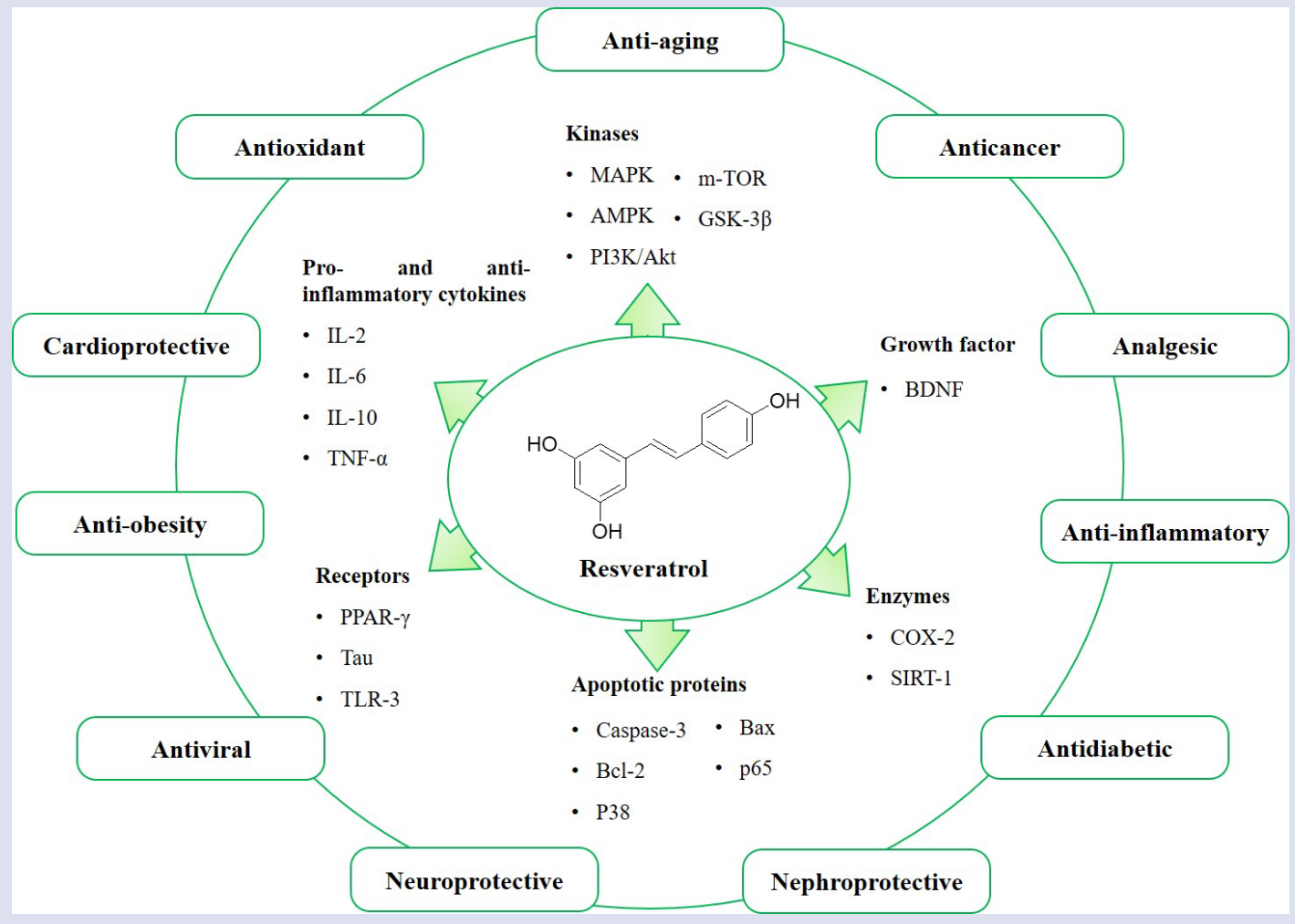

Cite this article: Saad NM, Sekar M, Gan SH, Lum PT, Vaijanathappa J, Ravi S. Resveratrol: Latest Scientific Evidences of its Chemical, Biological Activities and Therapeutic Potentials. Pharmacogn J. 2020;12(6)Suppl:1779-91. 